\title{
VELOCITY OF DEEP-SEA SEDIMENTS FROM SONOBUOY DATA
}

\author{
by \\ Robert Houtz, John Ewing, and Xavier LePichon
}

Technical Report No. 9

CU-9-68 NAVSHIPS N-00024-67-C-1186

April 1968 



\title{
Velocity of Deep-Sea Sediments from Sonobuoy Data ${ }^{1}$
}

\author{
Robert Houtz, John Ewing, and Xavier Le Pichon ${ }^{2}$ \\ Lamont Geological Observatory of Columbia University, Palisades, New York 10964
}

\begin{abstract}
Interval velocity solutions from sonobuoy data reveal three major sedimentary sequences: (1) Unconsolidated sediments whose velocity increases with depth of burial and ranges from 1.6 to $2.2 \mathrm{~km} / \mathrm{sec}$; (2) semiconsolidated sediments (layer A), which probably have some velocity discontinuities, whose velocity, increases with depth of burial and ranges from 1.7 to $2.9 \mathrm{~km} / \mathrm{sec}$; (3) consolidated sediments (layer $\beta$ ), measured in a few places, whose velocity is apparently independent of overburden and ranges from 2.7 to $3.7 \mathrm{~km} / \mathrm{sec}$. In the shallower layers, low velocities seem to be related to the deposition of clay-sized particles by relatively swift bottom currents; high velocities, to quieter bottom conditions or the influx of much turbidite material. Except for the shallow layers, velocity-depth functions are quite similar for the Gulf of Mexico and the Atlantic Ocean. All the curves show an increase of velocity with depth without significant velocity reversals.
\end{abstract}

\section{INTRODUCTION}

Sonobuoys (the SSQ-2S and SSQ-41 models) were first tested as geophysical instruments at Lamont in the summer of 1963 . These early tests were promising but did not yield good data. The technique was greatly improved by using directional receiving antennas aboard ship (to pick up the telemetered hydrophone output from the buoy), which increased the range to about 40 $\mathrm{km}$. The use of a pneumatic sound source (air gun) every 12 to 15 seconds provided excellent data density. By the beginning of 1966 sonobuoys were placed aboard Lamont research vessels and were used routinely to determine sediment velocities. In the meantime a computer program was developed to obtain accurate interval velocities. Details of the collection of data on shipboard and the computing procedures are explained in the companion paper. The reduction and correction of the sonobuoy data are based on the records of vertical reflection profiles recorded during the sonobuoy run. As a result, the solutions are unique even though the sonobuoy runs are not reversed. The sonobuoys are self-scuttling after about two hours in the water, and no attempet is made to retrieve them. Use of the sonobuoy station therefore involves no more than putting the

1 Lamont Geological Observatory Contribution 1167.

2 Now at CNEXO, 39 Av. de Iena, Paris, 17, France. buoy in the water and recording the buoy's signal while the ship is underway.

Sonobuoy records frequently show sub-bottom penetration that exceeds the depth recorded in the vertical profiler data by a factor of 3 or more. Refracted arrivals from consolidated sediments and the shallower crustal layers may also be recorded. Interval velocities, reflection times, refraction velocities, location, and other relevant information from each sonobuoy station are punched on IBM cards and stored for future reference. To date there are 220 cards in our files (one for each layer).

The accumulation of sedimentary velocities on a worldwide basis enables us to recognize trends in sediment velocities and to make some inferences about the geological history of the deep-ocean sediments. This paper attempts to describe the deep-sea sediments on the basis of their velocity characteristics and to make limited geological deductions.

\section{Discussion of Sonobuor Results}

The locations of sonobuoy measurements discussed in this paper appear in Figures 1 through 3. Table 1 lists all the sonobuoy data.

The standard deviation is based on the fit of a straight line to reduced $T^{2} / X^{2}$ data and is only strictly meaningful as a comparative standard of accuracy. A more detailed discussion of the observed deviations between adjacent profiles appears in the preceding paper [Le Pichon et al., 1968], which shows that the computed 


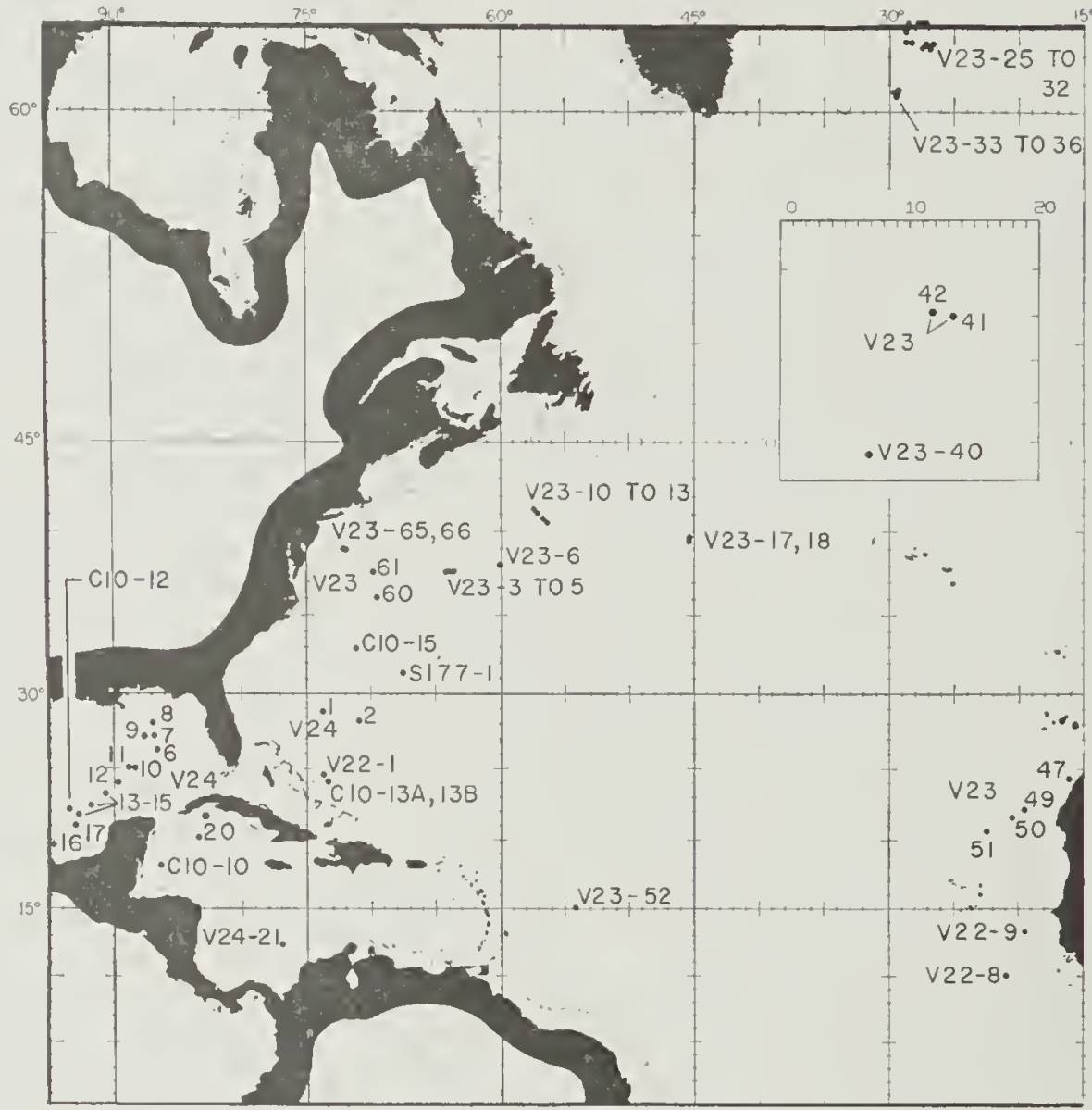

Fig. 1. Locations of sonobuoy stations in the North Atlantic with an inset of the NorwegianGreenland Sea.

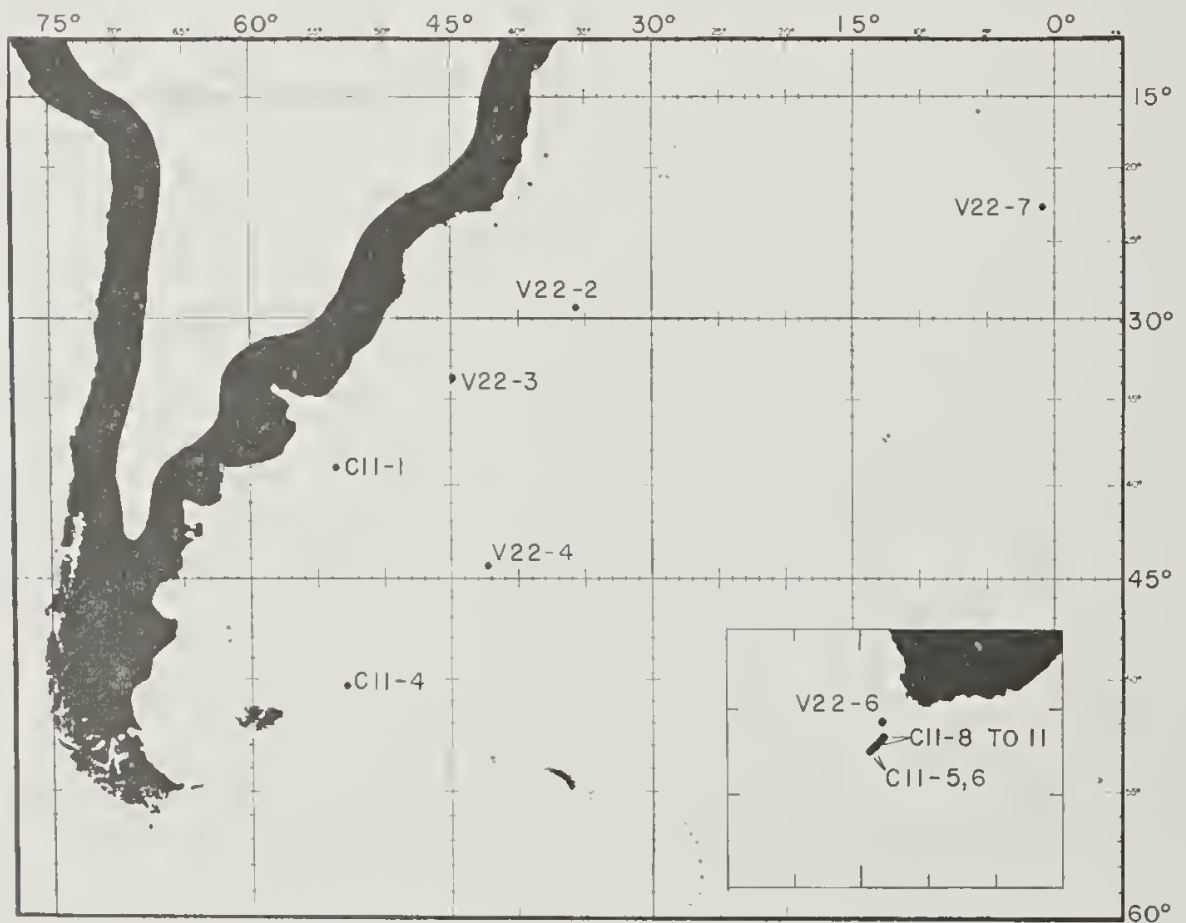

Fig. 2. Locations of sonobuoy stations in the South Atlantic with an inset of the Cape basin. 


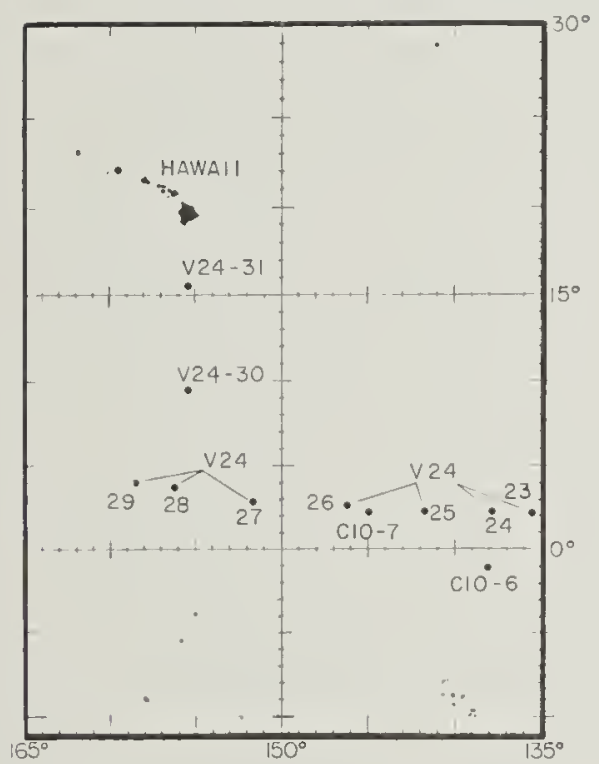

Fig. 3. Locations of sonobuoy stations in the eastern equatorial Pacific.

standard deviation is about $40 \%$ greater than the actual probable errors. The identification of horizons $A$ and $\beta$ is based on previous studies whenever possible. Elsewhere, the identification of these horizons is based on tentative correlations and is not final. There is no assurance that these reflection events are the same age throughout the Atlantic. Horizon $\mathrm{A}$ is a prominent reflector [Ewing et al., 1966] that has been identified as Upper Cretaceous from a major outcrop in the North Atlantic. It extends over much of the Atlantic but is not recognized throughout the mid-Atlantic ridge system and is lost as a discrete reflector on the upper continental rise. Horizon $\beta$ is a deeper prominent reflector dated as Lower Cretaceous (T. Saito, personal communication) from cored outcrops in the Atlantic. Horizon $\beta$ is more difficult to correlate, and it is inferred to be more widespread in the North Atlantic than in the South Atlantic. Apparently, horizon $\beta$ does not extend to the flanks of the mid-Atlantic ridge, so that its areal extent is less than that of horizon $A$.

Horizons $A$ and $\beta$ have been indicated in the figures that follow. The sonobuoy solutions appear in the line drawings below the photo copies of the original vertical profiler sections. Basement reflectors are hachured in the sonobuoy sections, and refraction velocities are shown by asterisks. Refraction velocities from unreversed sonobuoy stations are not always accurate due to the effects of slope and topography.

The uppermost layers are usually unconsolidated and are layered to varying degrees. Just below horizon A the sediments are usually densely stratified in the North Atlantic. There is a thick sequence of homogeneous sediments below this zone. Horizon $\beta$ usually marks the beginning of weakly stratified and more opaque sediments that rest directly on basement. To simplify discussion, layer $A$ is defined as the layer between horizons $A$ and $\beta$; layer $\beta$ is defined as the layer between horizon $\beta$ and basement.

North Atlantic. Profiler data and sonobuoy solutions from four areas in the Atlantic are shown in Figures 4 through 7 . Stations V23-49 and 50 (Figure 4) from the continental rise in the Canary Island-West Africa region illustrate a fairly complete stratigraphic sequence with velocities typically observed in the Atlantic. There is no assurance that our identification of layers $A$ and $\beta$ at stations $V 23-49$ and 50 are correct, but the acoustic properties support the identification. The deepest reflector in both profiles corresponds well (i.e., at the same reflection time below the sea surface) with identifiable basement reflections somewhat farther seaward. Note that the vertical reflection profile did not penetrate below horizon $A$, whereas two deeper reflectors were recorded in the sonobuoy data.

Stations V23-10, 11, 12, and 13 (Figure 5) from the Solm abyssal plain (at the foot of Grand Banks) reveal a more complex velocity structure. The velocities in the first layer are somewhat higher than usual, and these layers appear to be very densely stratified in the profiler records. As a consequence, there is no pronounced increase in velocity at horizon $\mathrm{A}$, although the lower third of layer $A$ has a velocity that significantly exceeds the velocity of the Tertiary sediments, which rarely exceed 2.2 $\mathrm{km} / \mathrm{sec}$. The basement surface is ordinarily too rough to obtain velocities in layer $\beta$ unless the vertical profiler data penetrate to basement, allowing approximate topographic corrections to be made. Penetration to basement was achieved with the sonobuoy but not with the profiler in much of the Solm plain area.

Sonobuoy stations C10-13A and 13B in Figure 6 are reversed over an area where horizon $A$ outcrops in the soutliwestern part of the North Atlantic. Station V22-1 (not shown) was 


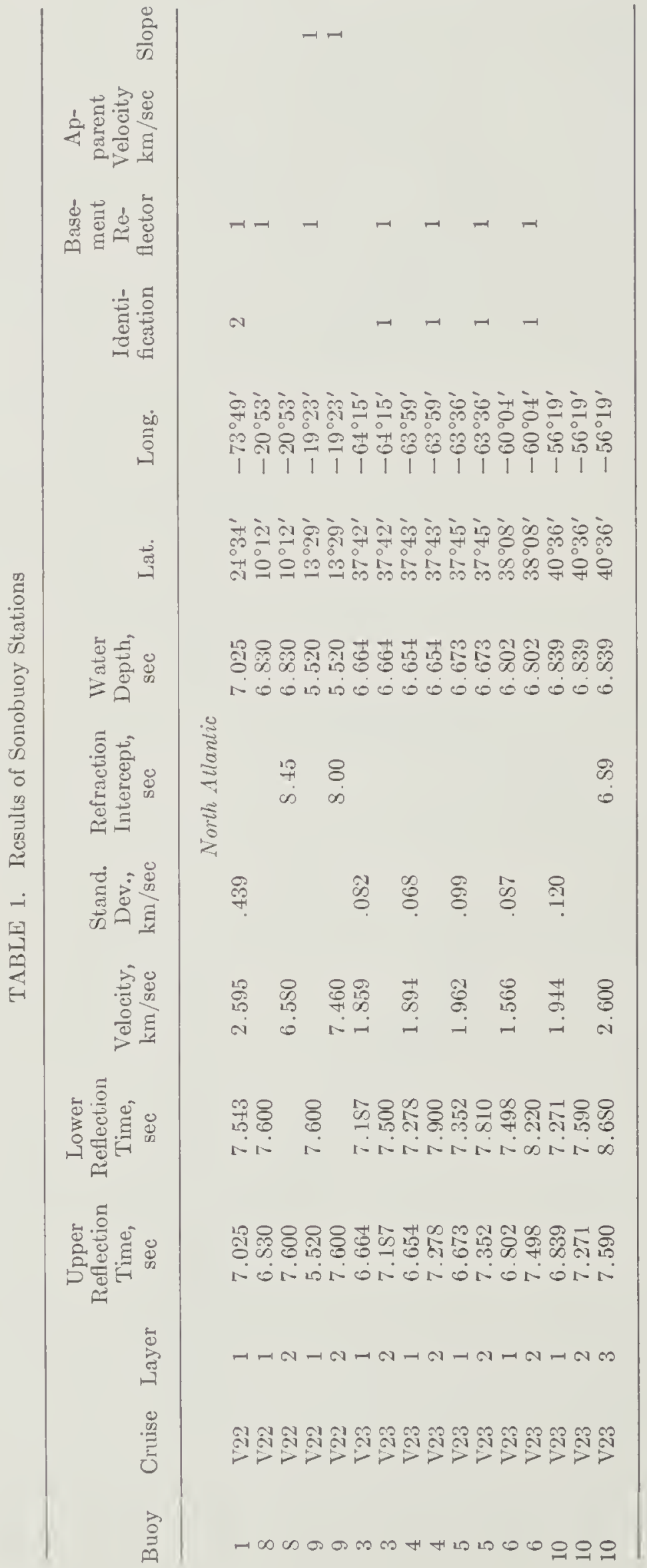

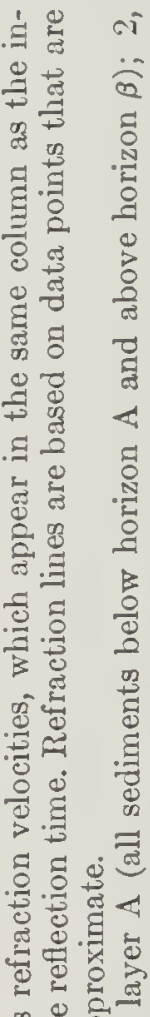

8

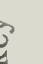




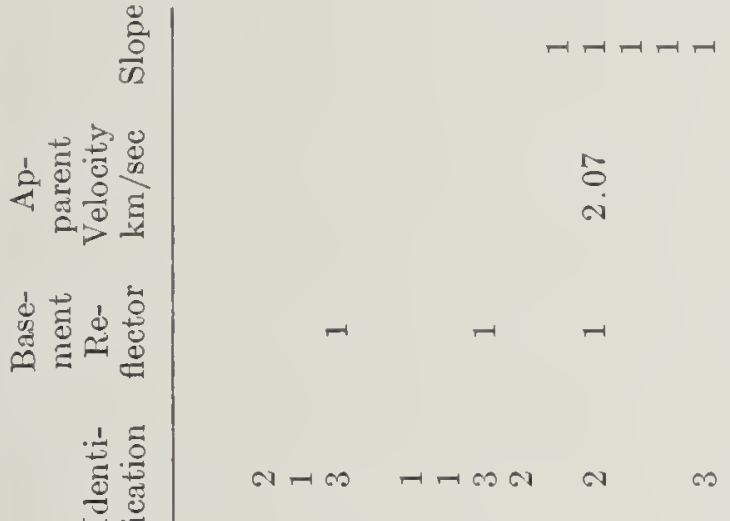

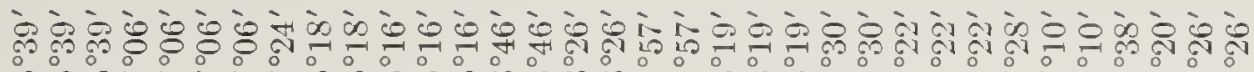

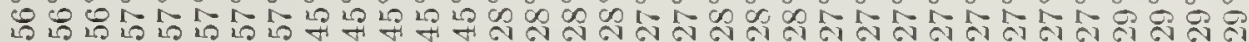
$1|1| 1|1| 1|1| 1|1| 1|1| 1|1| 1|1| 1|1| 1|1| 1 \mid 1$

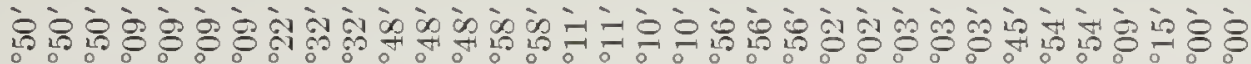

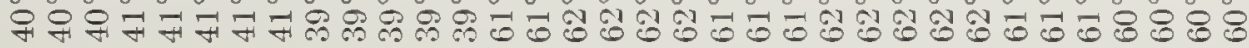

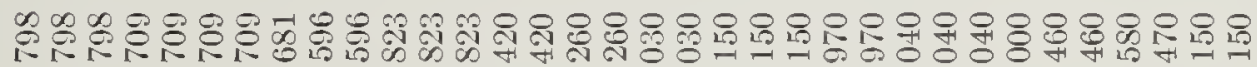

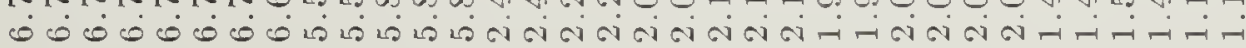

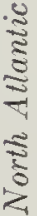

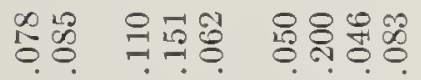

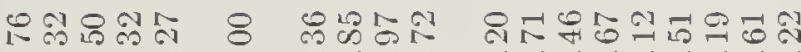

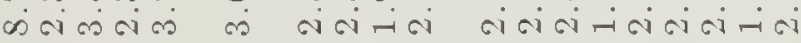

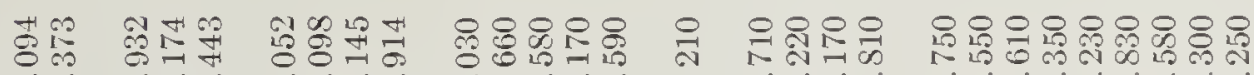

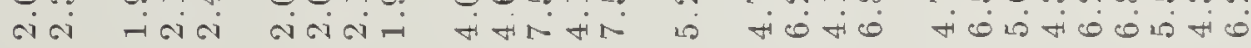

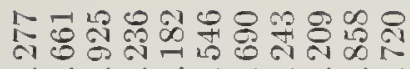

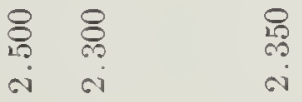

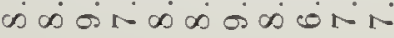

ก

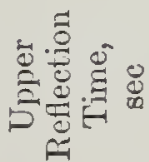

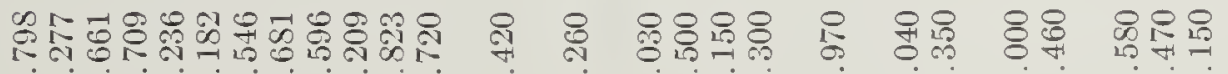

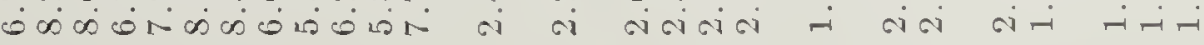

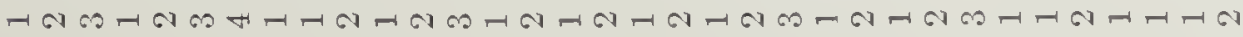

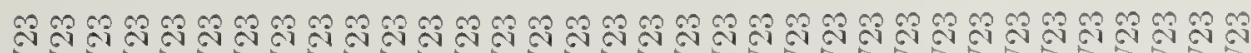




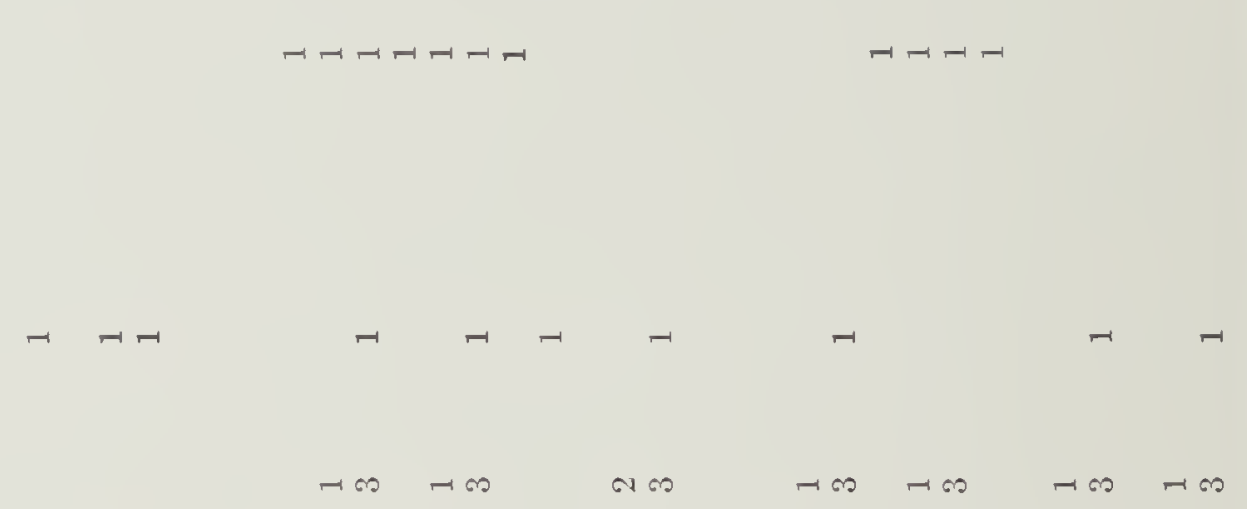

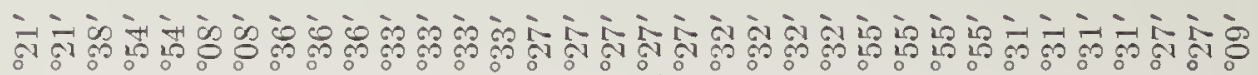
औ 1111111111111111111111111111111111

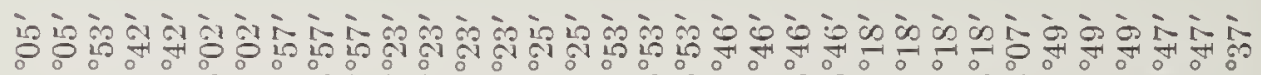

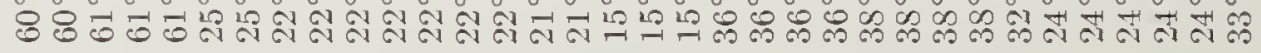

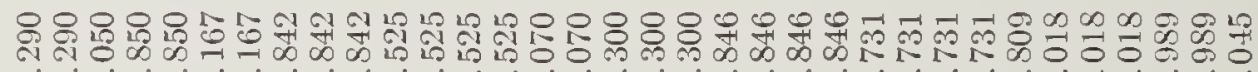

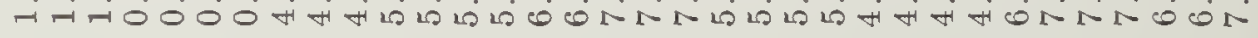
$\stackrel{\widetilde{\sim}}{\tilde{\Xi}}$

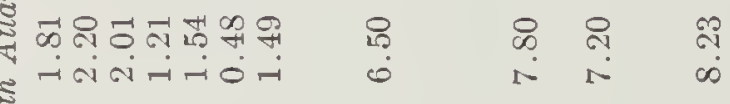

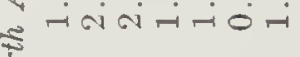
z

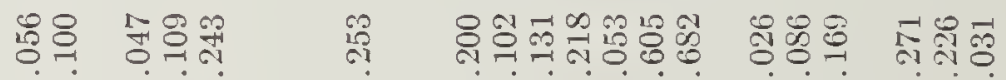

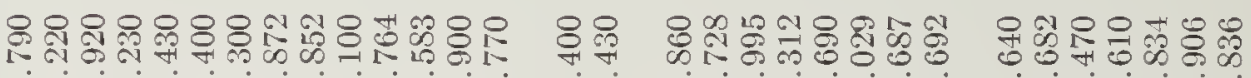

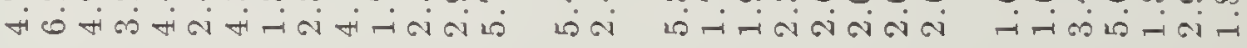

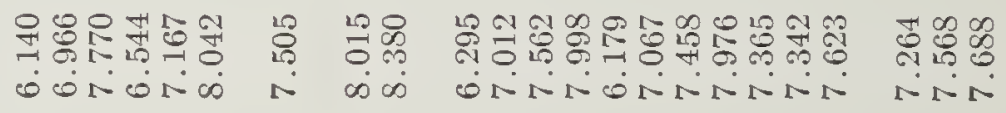

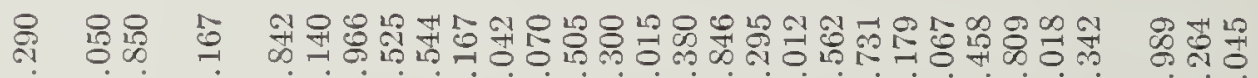

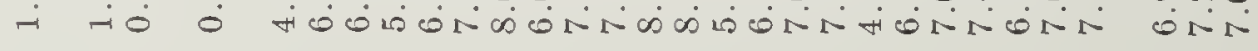

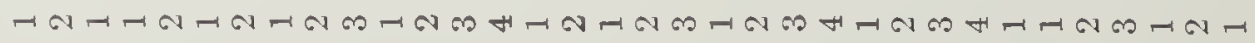

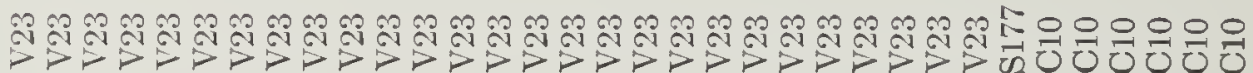

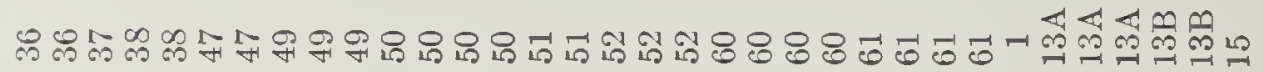




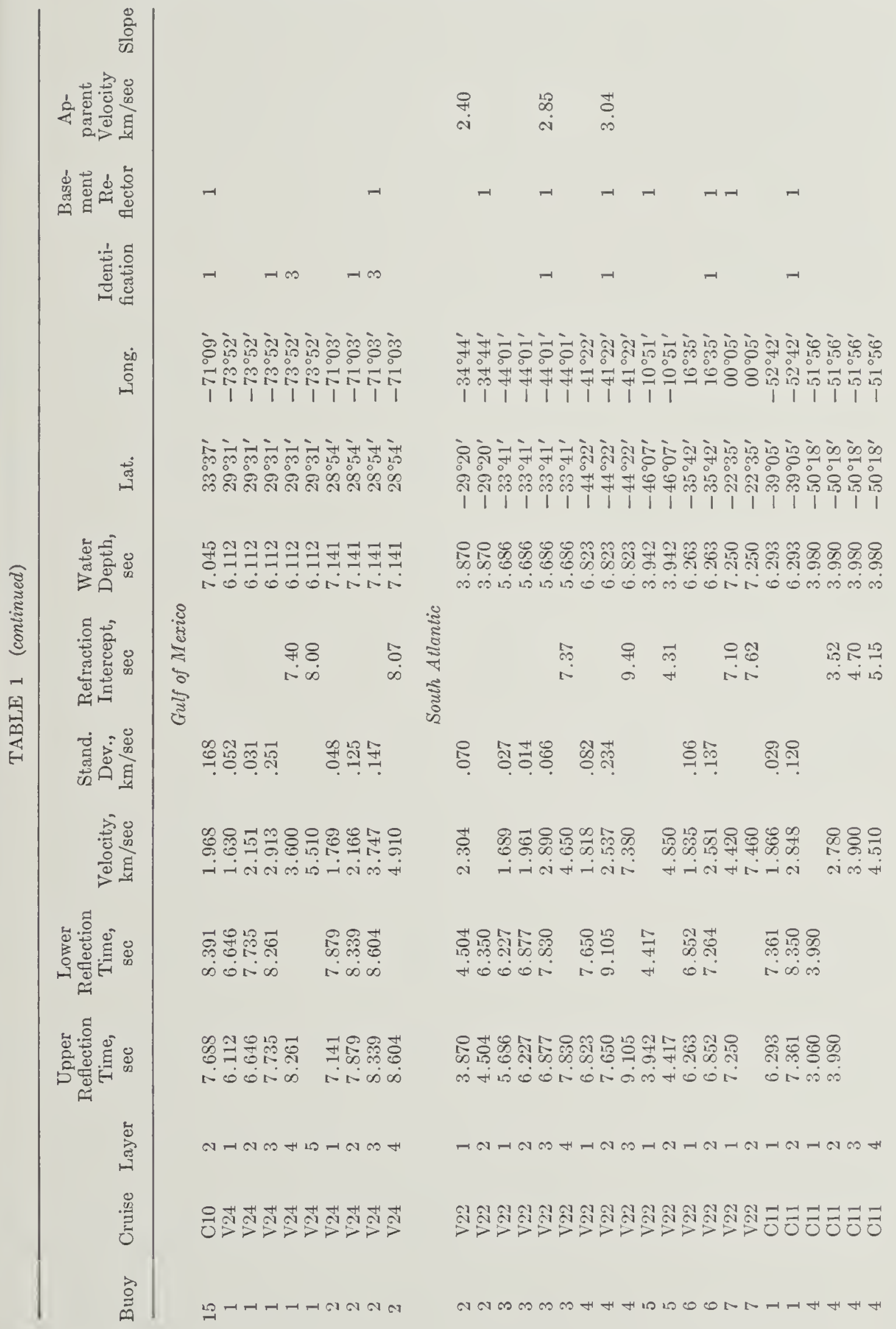




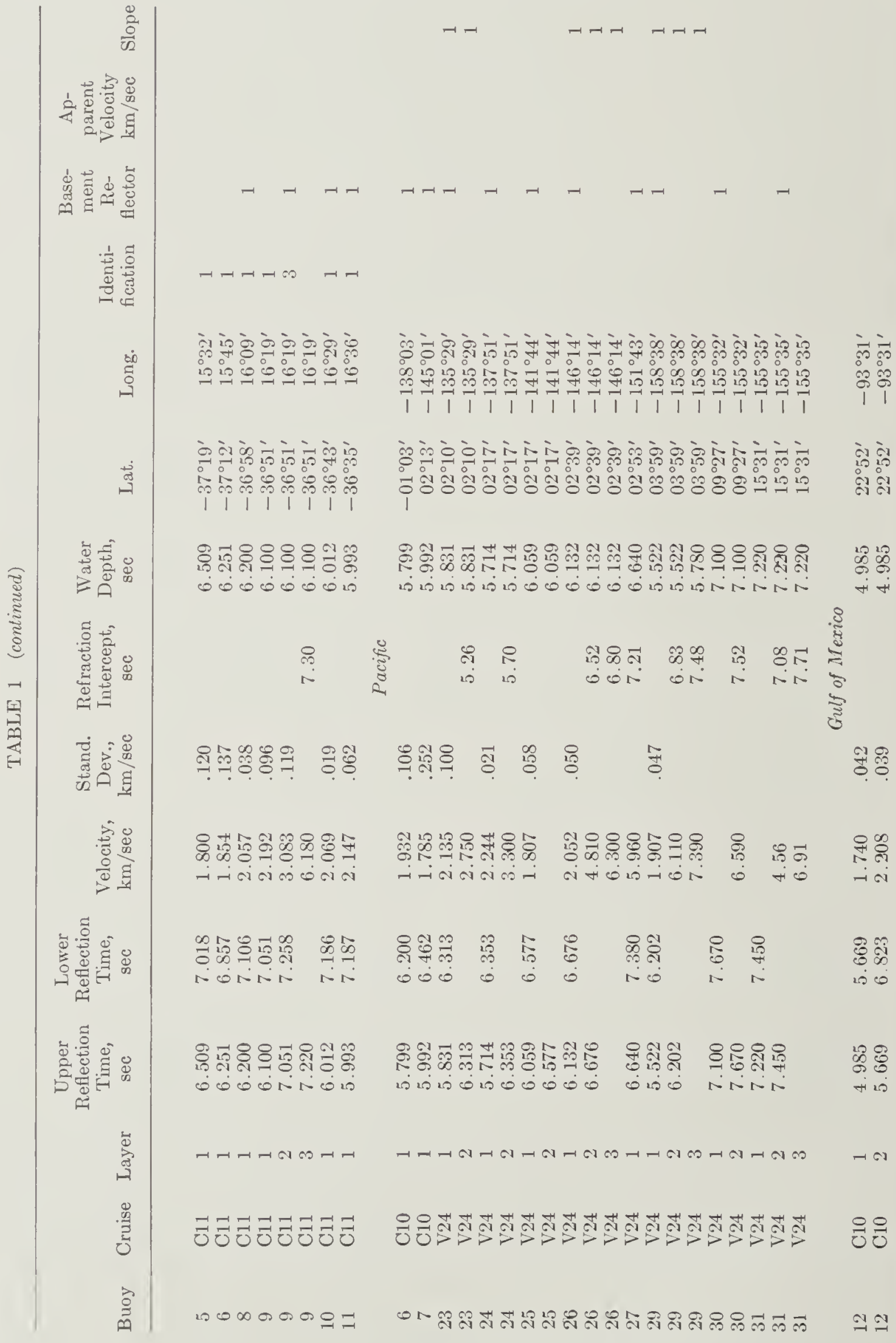




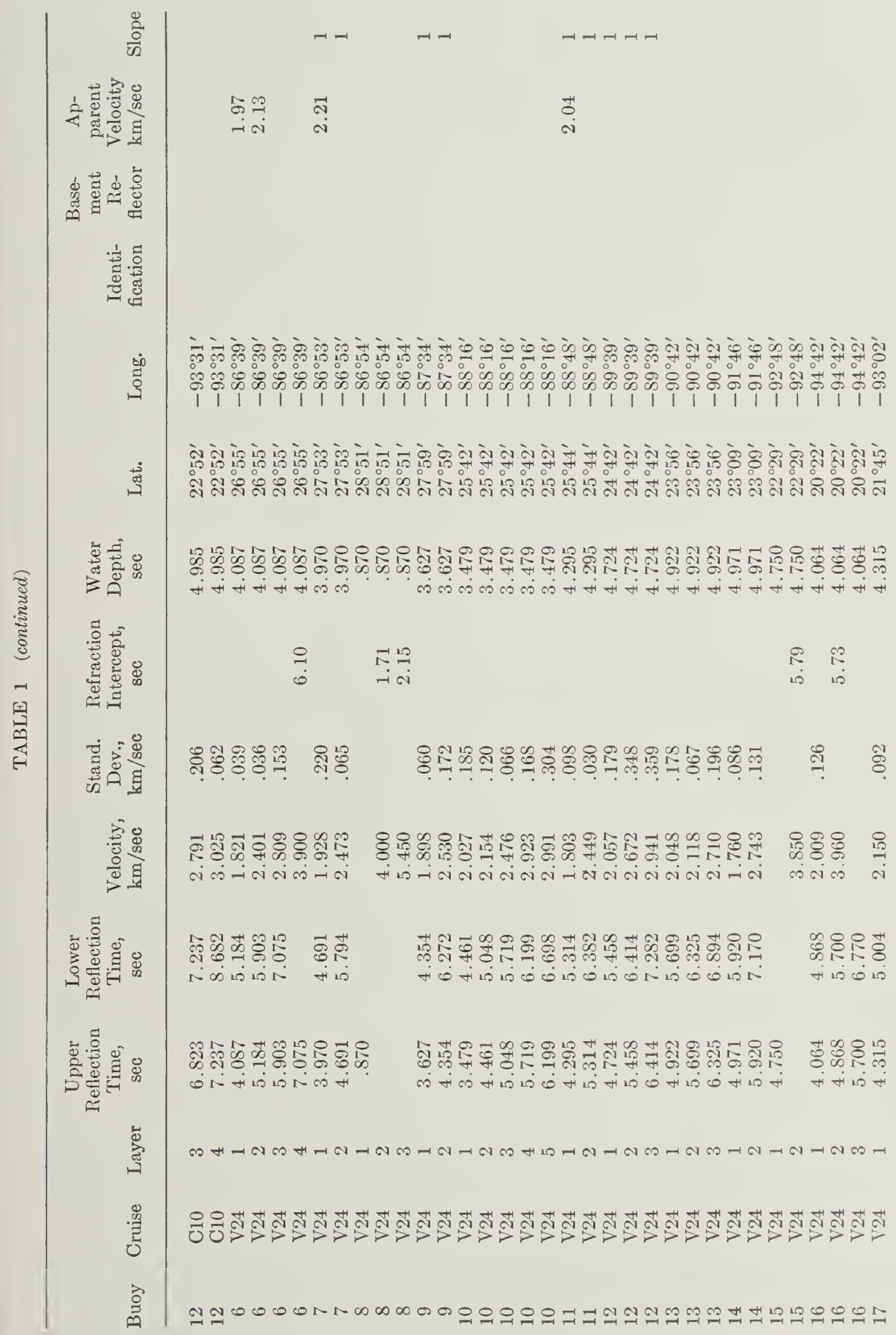


HOUTZ, EWING, AND LE PICHON

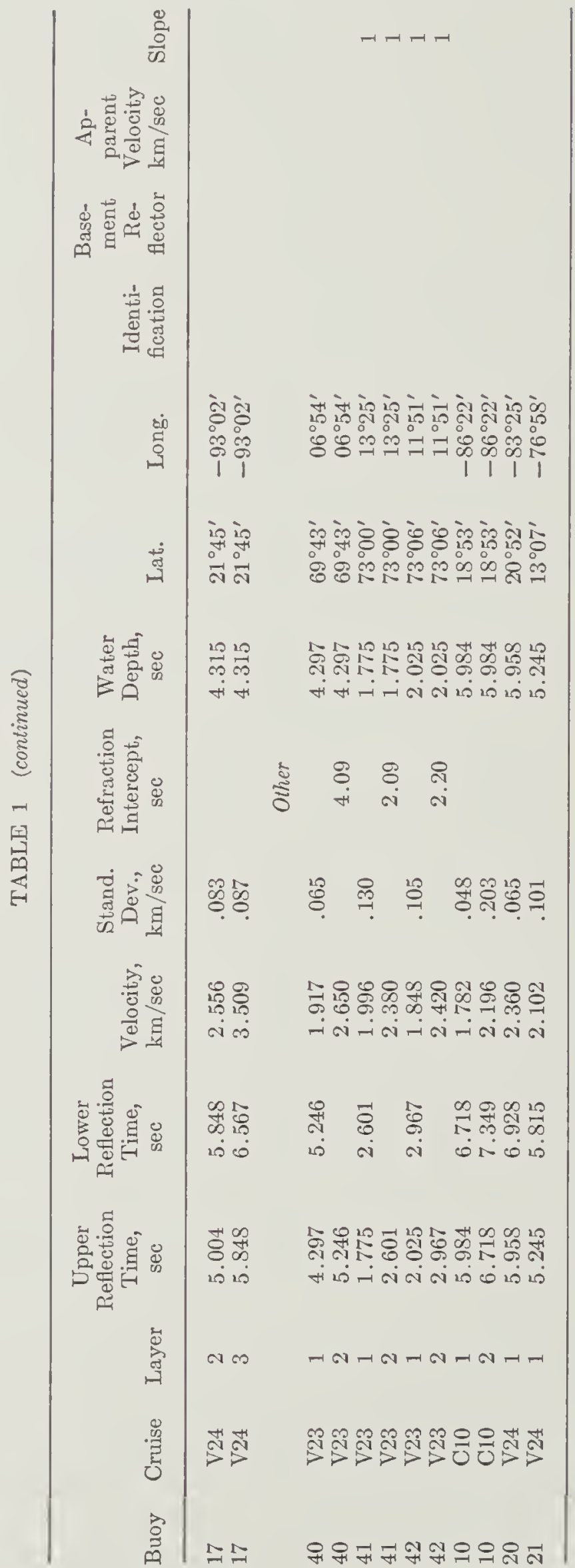



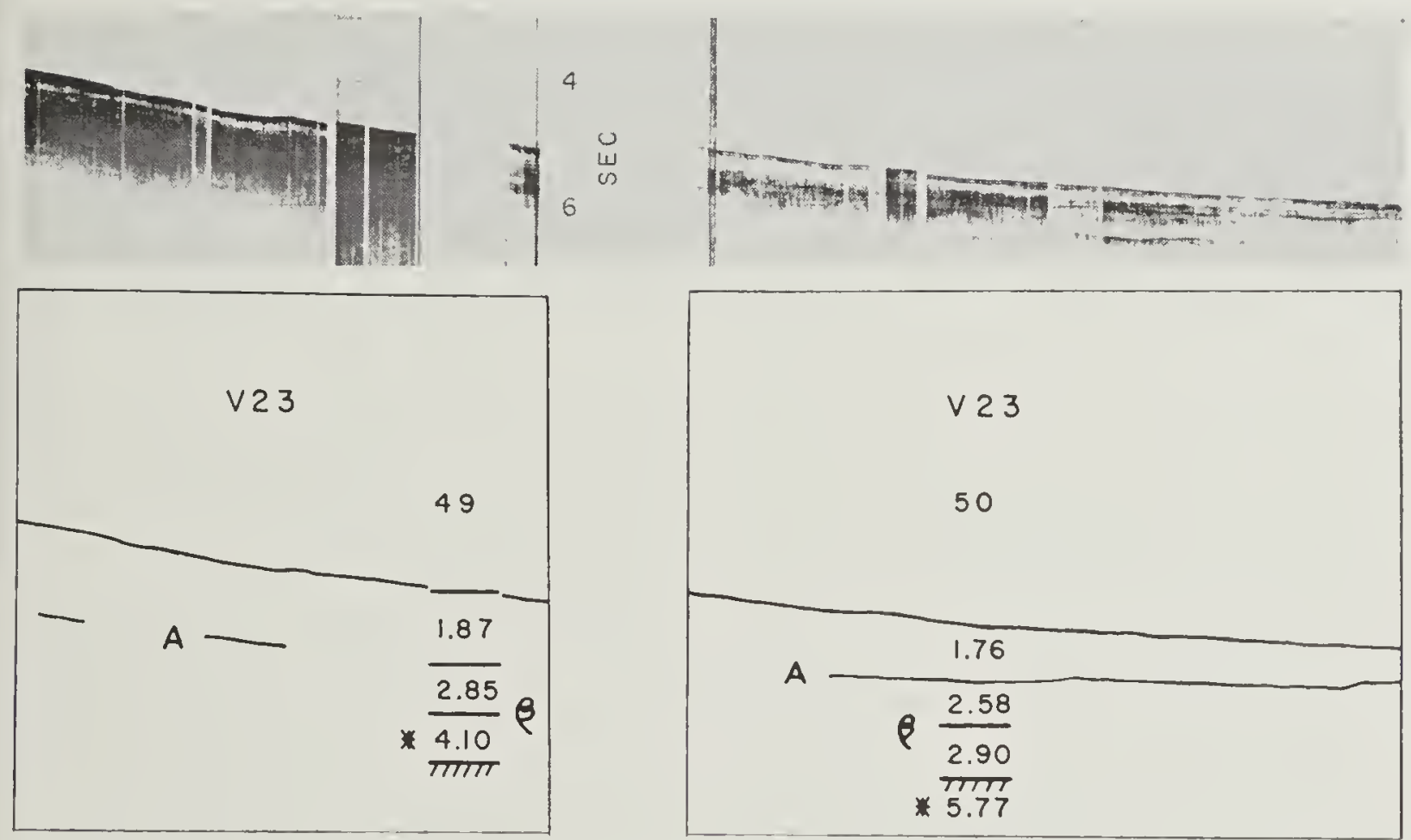

Fig. 4. Profiler and sonobuoy data near the Canary Islands.

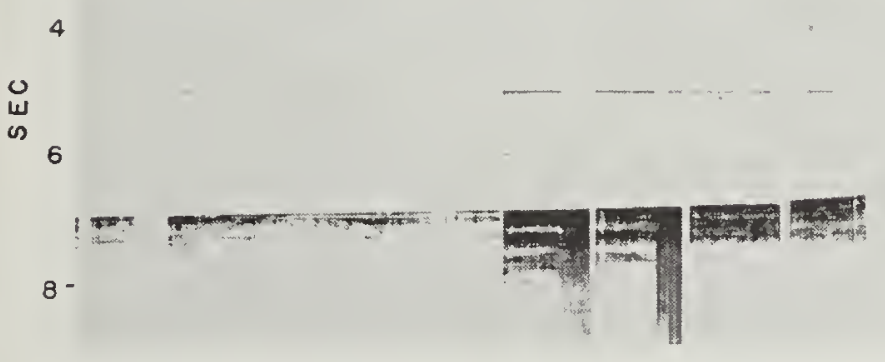

$\vee 23$

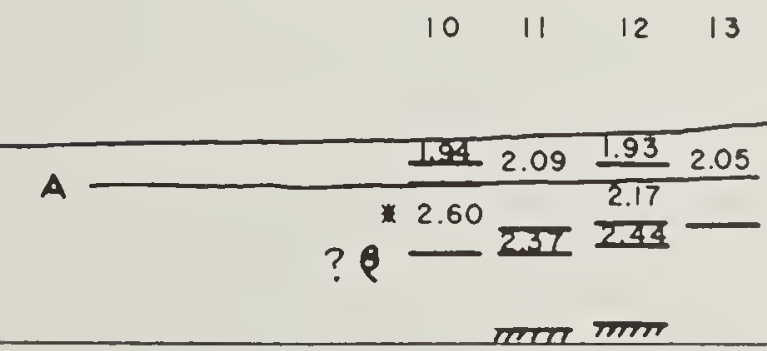

Fig. 5. Profiler and sonobuoy data near the Grand Banks. 


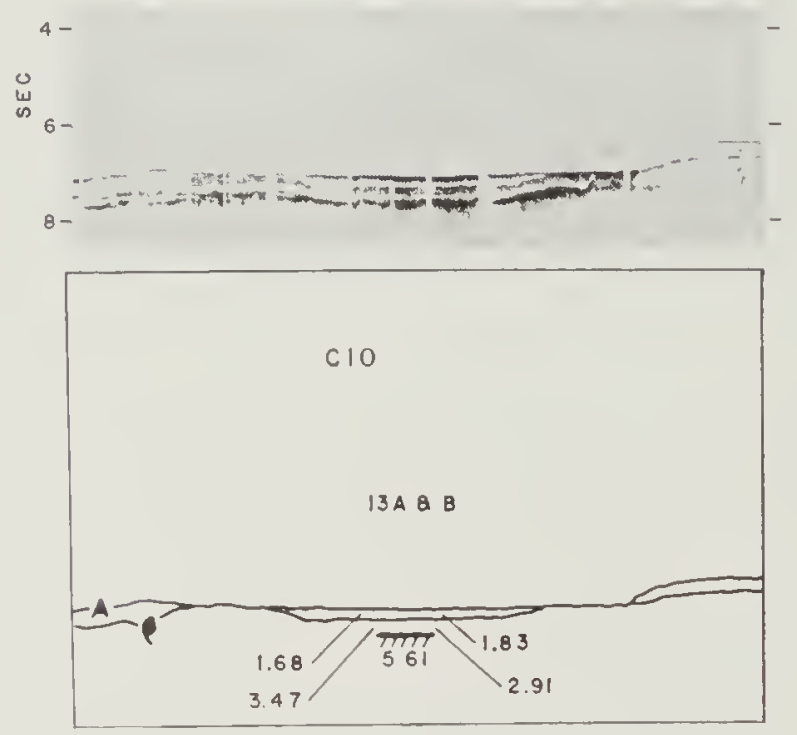

Fig. 6. Profiler and sonobuoy data from the outcrop area in the southwestern North Atlantic.

also shot in this area and gives a solution that agrees very well with the C10 stations (Table 1).

The very low velocities obtained from layer A strongly suggest that there never has been an appreciable Tertiary overburden. If the overburden once existed and was later removed, we would expect to record higher velocities resulting from compaction. We can probably discount later tectonic activity, which could reduce the velocity by introducing fractures, because the velocity in layer $\beta$ is consistent with the values found elsewhere. The velocity in layer $\beta$ secms to be independent of the depth of burial, because velocities of 3.0 to $4.0 \mathrm{~km} / \mathrm{sec}$ have becn observed in this layer under overburdens ranging from a few hundred meters to several kilometers. Cores from horizon A [Saito et al., 1966] reveal unconsolidated calcareous lutites and red clays, whereas cores from horizon $\beta$ reveal very hard deposits of dark mudstone, apparently consistent with a relatively high seismic velocity. Layer A has been sampled throughout most of its thickness down to horizon $\beta$ and in this area is consistently composed of unconsolidated material.

Stations V24-1 and 2 (Figure 7) were shot in the Blake-Bahama outer ridge area, $430 \mathrm{~km}$ north of stations $13 \mathrm{~A}$ and $13 \mathrm{~B}$. The velocity in layer $\mathrm{A}$ is $2.17 \mathrm{~km} / \mathrm{sec}$ at station 2 . The Tertiary sediments at station 1 are much thicker, and velocities were obtained in two layers above horizon A. The high velocity $(2.91 \mathrm{~km} / \mathrm{sec})$ in layer $\mathrm{A}$ at station 1 might be the mean velocity of layers $A$ and $\beta$, which have not been resolved separately here. A refraction (or wideangle reflection) velocity of $3.60 \mathrm{~km} / \mathrm{sec}$ was obtained at station 1 . This line appears to be very nearly tangent to the same reflection curve as the $5.51-\mathrm{km} / \mathrm{sec}$ refraction line, suggesting that the $3.60-\mathrm{km} / \mathrm{sec}$ material is quite thin. It is more likely that there is a real increase in the velocity of layer $\mathrm{A}$ caused by the great difference in the
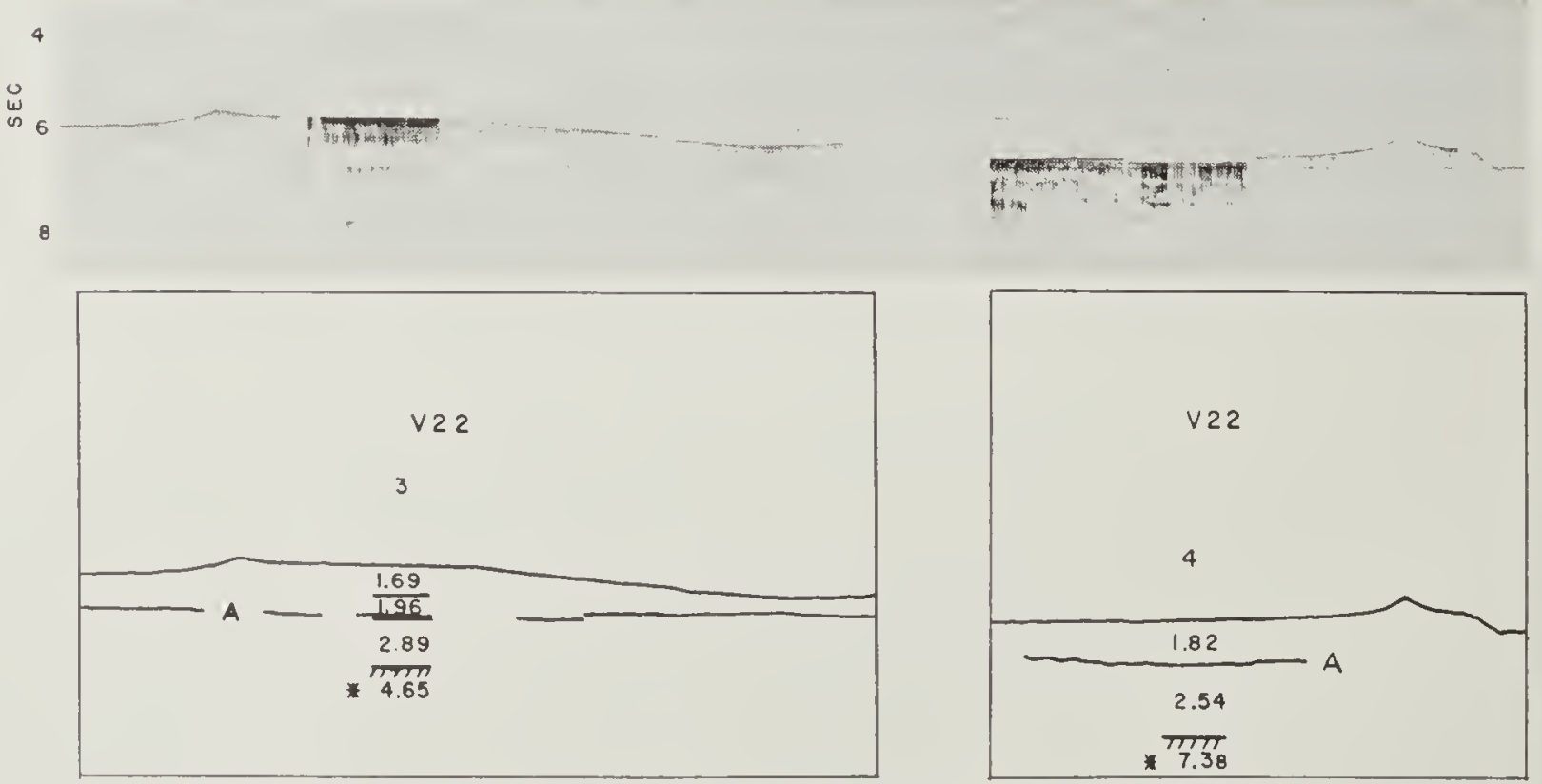

Fig. 7. Profiler and sonobuoy data near the Blake-Bahama outer ridge. 
thickness of the Tertiary overburden. The existence of high-speed sedimentary layers in the Blake-Bahama area has been demonstrated by Savit et al., [1964], Houtz and Ewing [1964], Northrop and Ransone [1962], and Bunce and Fahlquist [1962]. These authors observed refraction and interval velocities ranging from 3.0 to $4.2 \mathrm{~km} / \mathrm{sec}$.

The existence of critical refractions from horizon $\beta$ is crucial because it indicates a comparatively profound change in velocity. Only two other sonobuoy stations in the North Atlantic reveal possible critical refractions from the region of horizon $\beta$ (V23-18 and 49, see Table 1). Layer $\beta$ is ordinarily quite thim, so that the interpretation of the point of tangency is doubtful. Houtz and Ewing [1964], reporting data in the North Atlantic from two-ship experiments, noted that with source and detector near the sea surface (in deep water) refracted waves from sedimentary layers are not observed unless the velocity is greater than about $2.8 \mathrm{~km} / \mathrm{sec}$. This vahue agrees well with the lower limit of velocities we find in the present work for horizon $\beta$. It is also possible that the $3.60-\mathrm{km} / \mathrm{sec}$ line at station $\mathrm{V} 24-1$ represents a critically refracted shear wave from basement. If Poisson's ratio is 0.25 , the shear wave would have a velocity of $3.2 \mathrm{~km} / \mathrm{sec}$, a value that is probably within the limits of accuracy of refraction velocities at station V24-1.

A more detailed discussion of critical shear wave refractions (including some new data that bear on sonobuoy solutions) appears in Appendix 1 along with the discussion of refractions from thin layers.

South Atlantic. The profiler data and the sonobuoy solutions from the Argentine basin and from the continental rise west of South Africa (Cape basin) appear in Figures 8 and 9 . Stations V22-3, V22-4, and C11-1 (not shown) were shot in the Argentine basin. In each case horizon $\mathrm{A}$ is associated with a velocity discontinuity, and layer $\beta$ is not identifiable. Le Pichon et al. [1968] in the companion paper discuss station V22-3 in some detail and show that the velocity discontinuity at horizon $A$ is required to account for the behavior of the wide-angle data; i.e., the data cannot be reconciled with a gradual increase in velocity above horizon A (to the value measured for layer A) with little or no velocity discontinuity across the boundary.

The C11 stations (Figure 9) were shot end to end in a region where the sedimentary cover on basement gradually thickens toward the continent to the northeast. The results suggest an increase of interval velocity as the layer
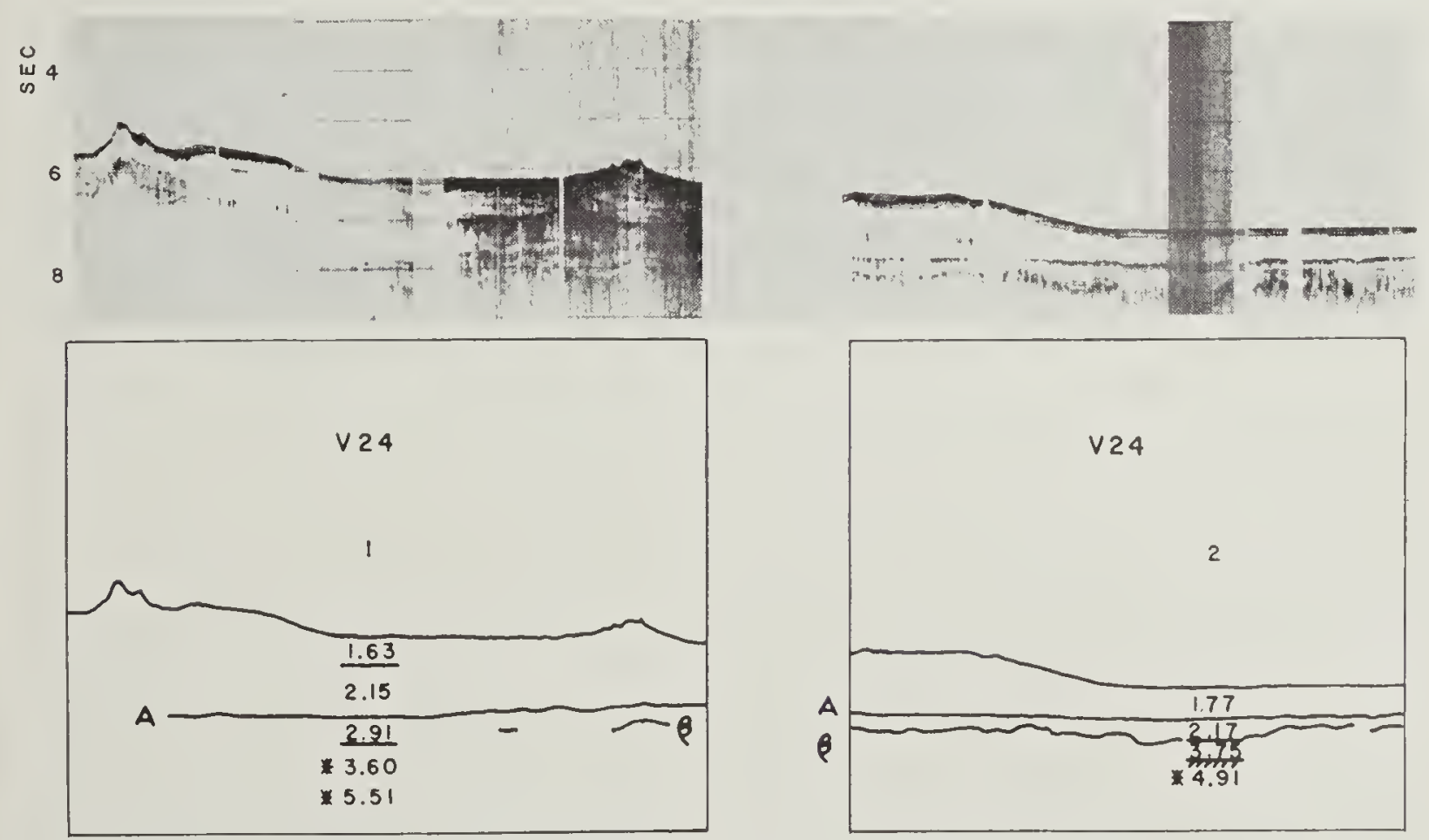

Fig. 8. Profiler and sonobuoy data from the Argentine basin. 

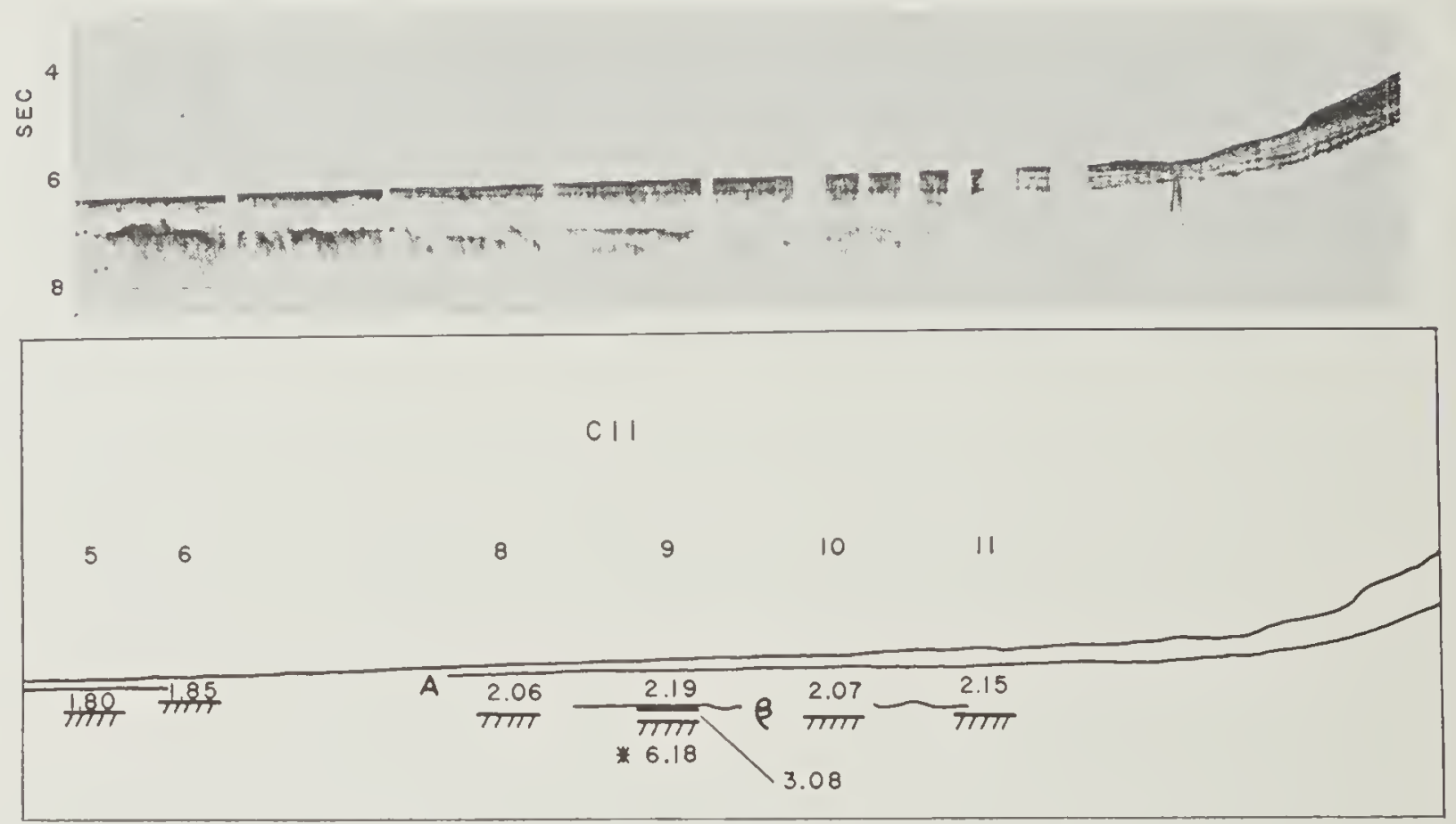

Fig. 9. Profiler and sonobuoy data from the Cape basin.

thickens, confirming the existence of positive velocity gradients. The sediment velocities in these profiles are significantly higher than the velocities observed elsewhere in the Atlantic. Sediment cores and bottom photographs reveal a hard atypical sea floor. Station 9 shows a $3.08-\mathrm{km} / \mathrm{sec}$ sediment layer lying directly on rough basement. We interpret this layer to be layer $\beta$ and the very shallow reflector to be horizon $A$. If this interpretation is correct, these sediments are largely pre-Tertiary, which provides a partial explanation of their unusually high velocities. The solutions in layer $\beta$ at C11-9 should be accepted with caution because the layer is only a few wavelengths thick.

Station V22-6 (not shown), which is about $50 \mathrm{~km}$ north of C11-11, has been discussed in the companion paper. The sonobuoy record shows a prominent reflector that does not appear in the profiler record, even though a strong basement reflection appeared below the horizon in the profiler data. This effect was attributed to a velocity transition zone that is small in comparison to wavelengths in the sonobuoy data (150 meters) but is large in comparison to wavelengths in the profiler data (15 meters). Judging by the sonobuoy data of station V22-6, a transition zone (at the top of a $2.58-\mathrm{lm} / \mathrm{sec}$ layer) may correspond to reflector $\beta$.
King [1962], among others, has suggested that parts of the North Atlantic are older than the Soutl Atlantic. The concepts of sea-floor spreading and continental drift require that layer $\beta$ occurs at about equal distances from the continents bordering both oceans, if the conditions of origin and deposition were similar, and the basins are the same age. Our data at this writing suggest that layer $\beta$, which is widely observed in the North Atlantic, is either missing or occurs locally near the continents in the South Atlantic. If layer $\beta$ is present over wide areas in the South Atlantic, it is not a good reflector, does not propagate detectable critical refractions as it apparently does in the North Atlantic, and does not yield interval velocities as high as those observed in the North Atlantic (3.0 to $4.0 \mathrm{~km} / \mathrm{sec}$ ). Sediment origin may be quite different in the two oceans, however; certainly there is no counterpart of the Appalachian system on the coast of Argentina. Large parts of the Argentine abyssal plains are difficult to penetrate by the profiler technique, but a prominent reflector has been recorded in the Argentine rise below horizon A [Ewing et al., 1964]. The work of Ewing et al. reveals no sediment velocities greater than $2.4 \mathrm{~km} / \mathrm{sec}$.

Gulf of Mexico. Stations V24-6, V24-7, and V24-9 through 14 appear in Figures 10 and 11. 

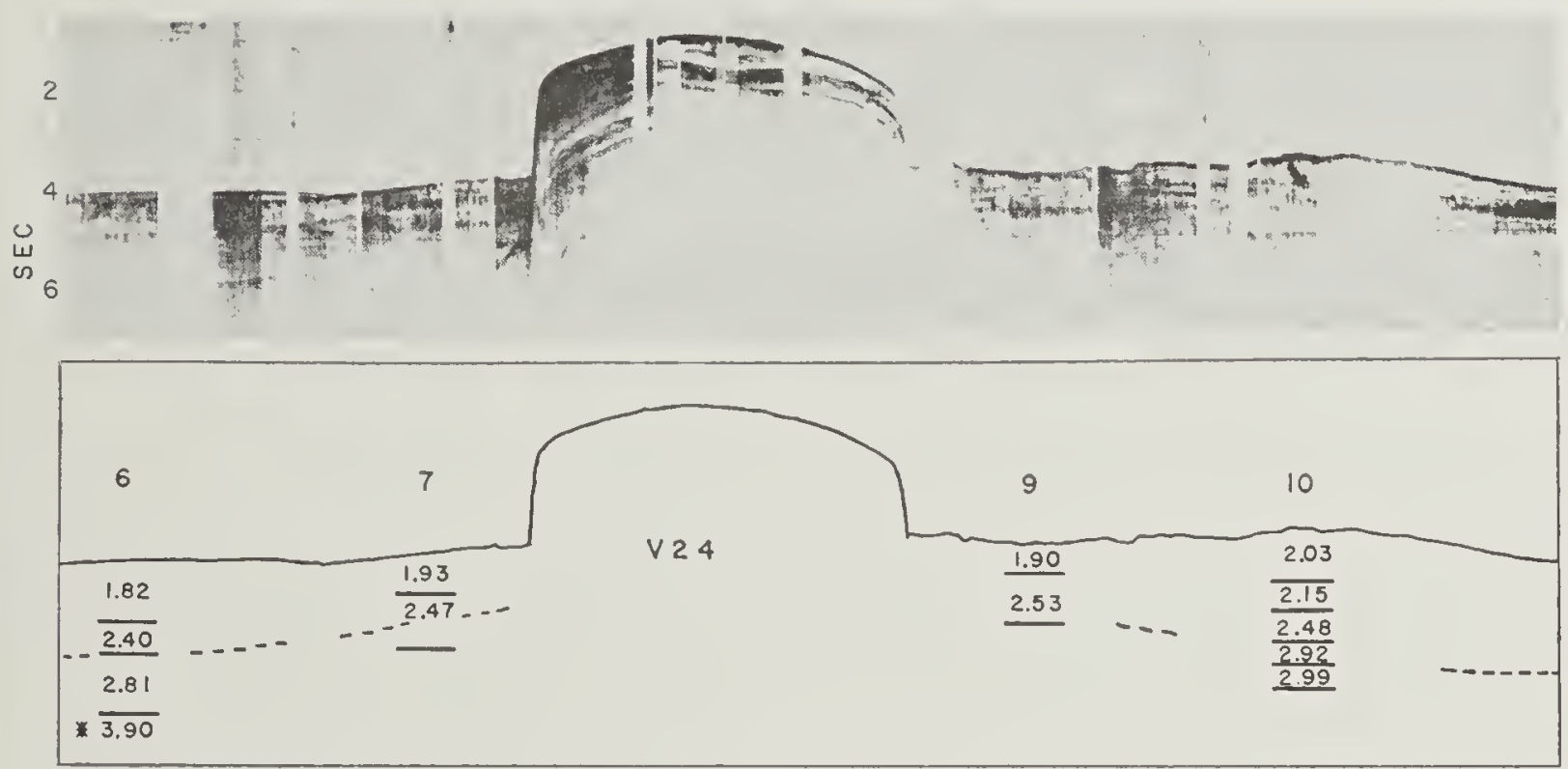

Fig. 10. Profiler and sonobuoy data from the Gulf of Mexico.

The data of $\mathrm{C} 10-12$ are shown to the north of V24-14 for comparison. A well-defined reflector occurs in these profiles and is shown with a dashed line in the sections. This reflector clearly marks a sedimentary event with the velocities below it ranging from 2.71 to $3.00 \mathrm{~km} / \mathrm{sec}$. The knoll-like structure in Figure 10 is illusory because it occurs at a major course change along the profiler track. The deepest detectable layer in these profiles shows a refraction velocity of $3.90 \mathrm{~km} / \mathrm{sec}$ at V24-6. Similar velocities are not recorded again until the sea floor changes char- acter beyond station V24-14. Refraction velocities of 3.55 and $3.96 \mathrm{~km} / \mathrm{sec}$ and an interval velocity of $3.51 \mathrm{~km} / \mathrm{sec}$ were recorded to the south in the Bay of Campeche. Here the highspeed layer has risen to shallower depths, as shown by the profiler sections. The results of the present work show an excellent agreement with the work of Ewing et al. [1960, 1962] and Antoine and Ewing [1963]. Much of this earlier work was based on refraction data in the central abyssal plain and the Bay of Campeche, where the present data were obtained.
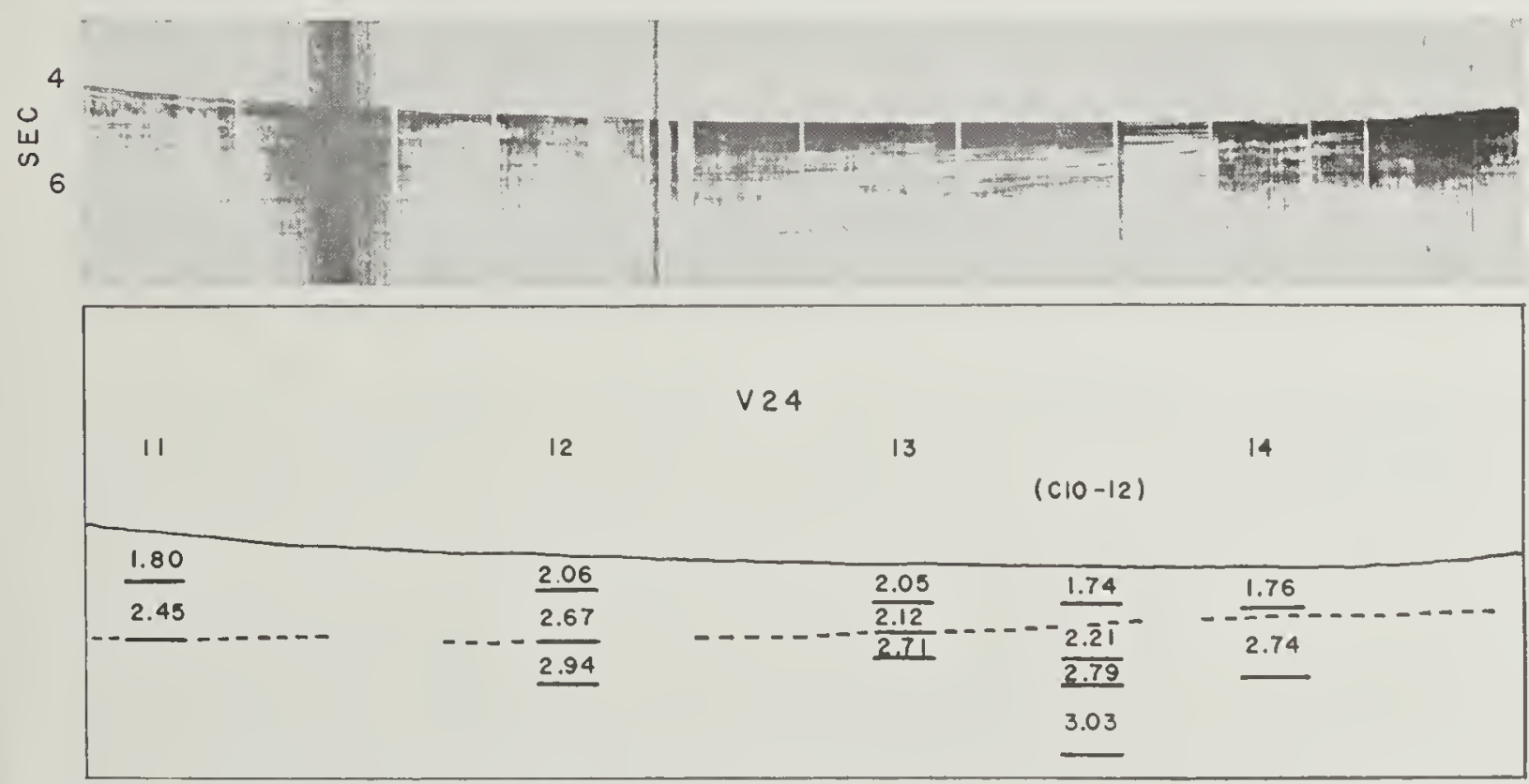

Fig. 11. Profiler and sonobuoy data from the Gulf of Mexico. 
Pacific. The thin sediments encountered on cruise V24 in the eastern equatorial Pacific limited the velocity study to single-layer solutions. The velocities in the sediments are higher than those typically observed in the Atlantic at comparable depths of burial. Well-recorded refractions from basement and the oceanic layer are characteristic of the area.

Short profiler sections are shown in Figure 12, which includes stations V24-25 and 29. The thin layer that appears around station 29 was not recorded elsewhere on this crossing. Its velocity was not resolved separately (owing to large dips and rough topography), but it has no obvious effect on the velocity solution down to basement.

The reflection data from the basement interface yield velocities ranging from 4.56 to 6.11 $\mathrm{km} / \mathrm{sec}$, and the velocities from the oceanic interface range from 6.11 to $7.39 \mathrm{~km} / \mathrm{sec}$. The variability of these solutions is probably due to dip, as evidenced by the occurrence of high (or low) velocities from both layers at the same station. The data have not been corrected for basement topography.

\section{Analysis of Sediment Velocities}

Interval velocities from 102 sonobuoy solutions appear in Figure 13. These velocities are based on all the solutions obtained to date. The interval velocities are plotted against one-way vertical travel time to the midpoint (in time) of the layer. Solutions from layer A and layer $\beta$ and velocities that combine two types of layer are identified separately in the plot. These identifications apply only to the Atlantic data and are subject to interpretation. The vertical line through the data points is equal to twice the computed standard deviation, which is somewhat less than the $90 \%$ confidence limits (see preceding paper). The standard deviation of the computed velocity that results from the scatter in the data at any one station has a nearly constant relation to observed deviations between adjacent stations. The computed standard deviation is about $40 \%$ higher than the actual errors. Consequently, the tabulated standard deviations in Table 1 have a real significance, which means that conclusions to be drawn from the data can be done within prescribed limits of confidence. For example, the average computed standard deviation of all the solutions is $126 \mathrm{~m} / \mathrm{sec}$, which gives significance to the observation that velocity reversals have never been recorded at any of the stations.

We can see in Figure 13 that the greatest deviations are produced by solutions from layer $\beta$. This is understandable because layer $\beta$ is relatively thin, occurs at variable depths below the sea floor, and has uniformly high velocities, apparently independent of the overburden. We

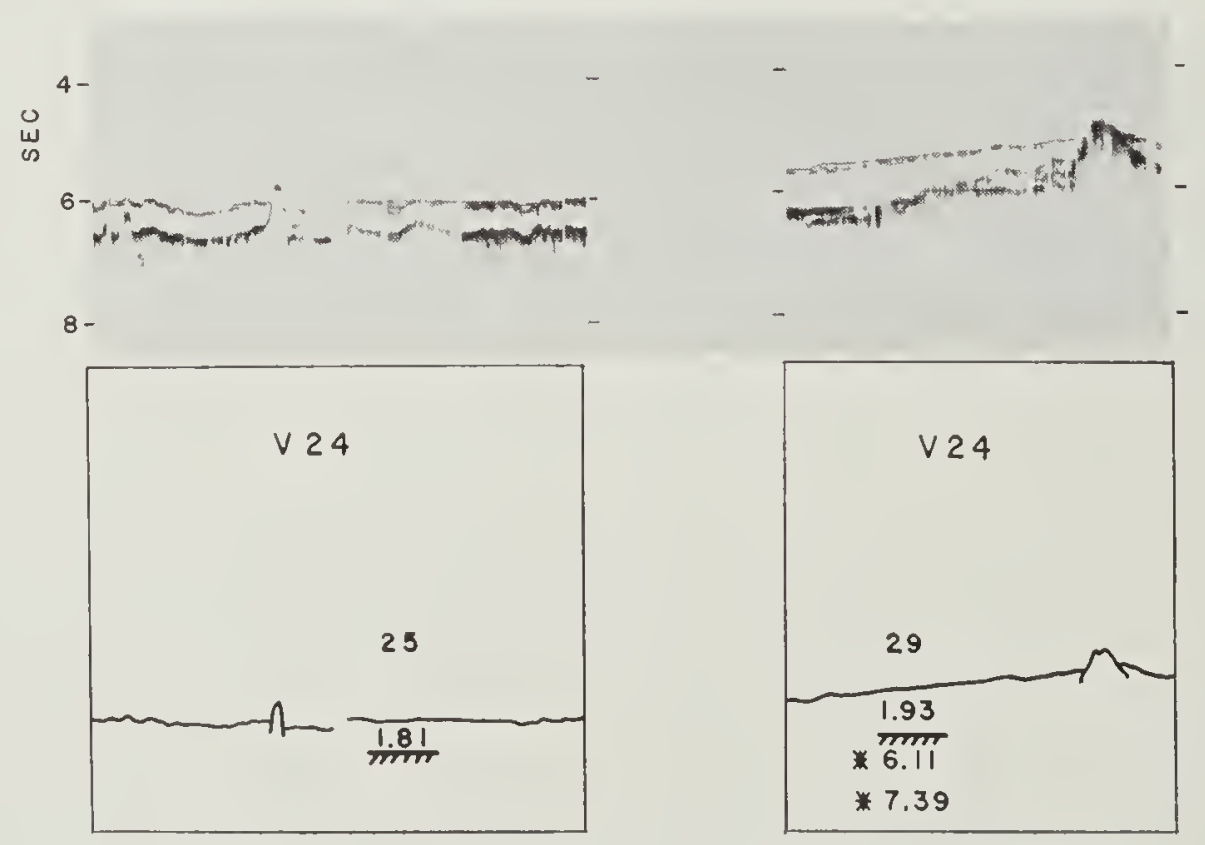

Fig. 12. Profiler and sonobuoy data from the eastern equatorial Pacific. 


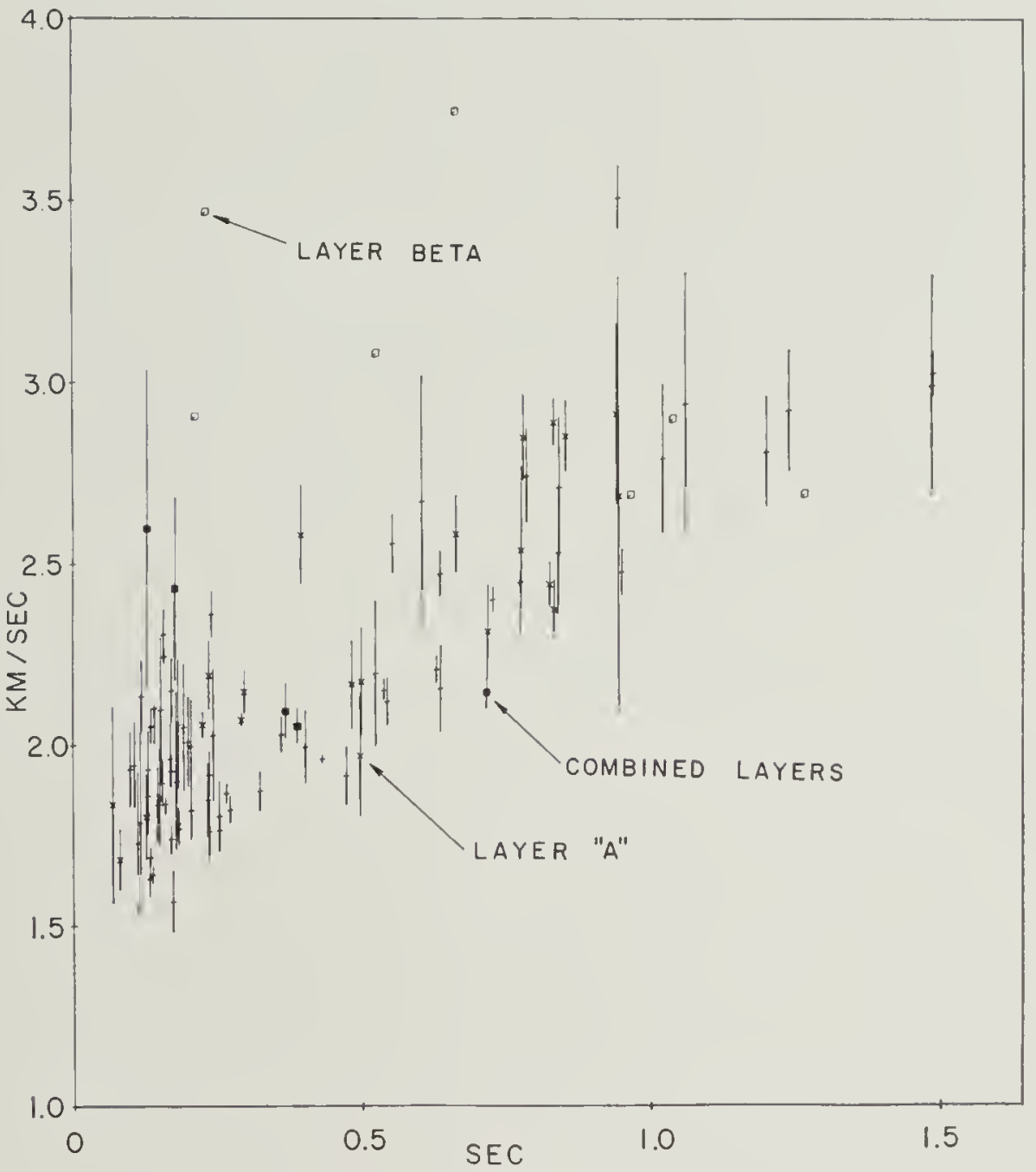

Fig. 13. Interval velocities of all sonobuoy solutions.

might also expect to reduce the scatter by removing solutions from layer $A$, solutions that combine two types of layer, and by investigating geographical regions individually. The effects of these and other factors will be discussed below.

All the velocity plots in the following discussion are based on velocity versus one-way vertical travel time. The major advantages of this method in comparison to plots of velocity versus computed depth are:

1. Greater accuracy in the plot because propagated errors in the depth computation do not appear.

2. Mean velocity plots lead directly to deptl as a function of one-way travel time.

3. The differential-type operation that leads to instantaneous velocity from the mean veloc- ity yields a simple and exact solution (if polynomial expressions are used).

In each case the curves shown are third-order polynomials fitted by least squares. Instantaneous velocity curves will be used to compare different sets of velocity data, because these curves are more sensitive to velocity variations with depth. Instantaneous velocity curves may be obtained approximately by plotting interval velocities against one-way travel time to the midpoint (in time) of the layer (as in Figure 13) from which the velocity is obtained. A polynomial is then fitted by least squares to the interval velocities. The expression obtained can be used to calculate the small errors introduced by the nonlinearity of the velocity-depth variation and to obtain 'corrected' interval velocities more nearly equal to the instantaneous veloci- 
ties at the same depths in time. The instantaneous velocity-depth curve is found by fit to the 'corrected' interval velocities. The values of instantaneous velocities found in this way are inherently superior to the values found by differentiating the mean velocity curve. That is to say, the distortions amplified by differentiating the mean velocity curve yield an instantaneous velocity curve that is systematically below the observed interval velocities at the greater depths. A more detailed discussion of the velocity curves appears in Appendix 2. Each point in the plots is weighted as an inverse function of its standard deviation before the fit is made. The weight is $0.5+.05 / \mathrm{s} . \mathrm{d}$, i.e., a weight of 1.00 for a standard deviation of $0.10 \mathrm{~km} / \mathrm{sec}$. The velocity at the water-sediment interface ( $T=0 \mathrm{sec}$ ) has been accurately determined in the Atlantic with in situ measurements involving the observation of phase changes in reflections at grazing incidence [Houtz and Ewing, 1964] and with velocimetric measurements in fresh piston cores [Schreiber, 1966]. The velocity at this point $1.52 \mathrm{~km} / \mathrm{sec}$, has been greatly weighted to constrain the fit to pass through this point. The same value has been assumed for the data for the Gulf of Mexico.

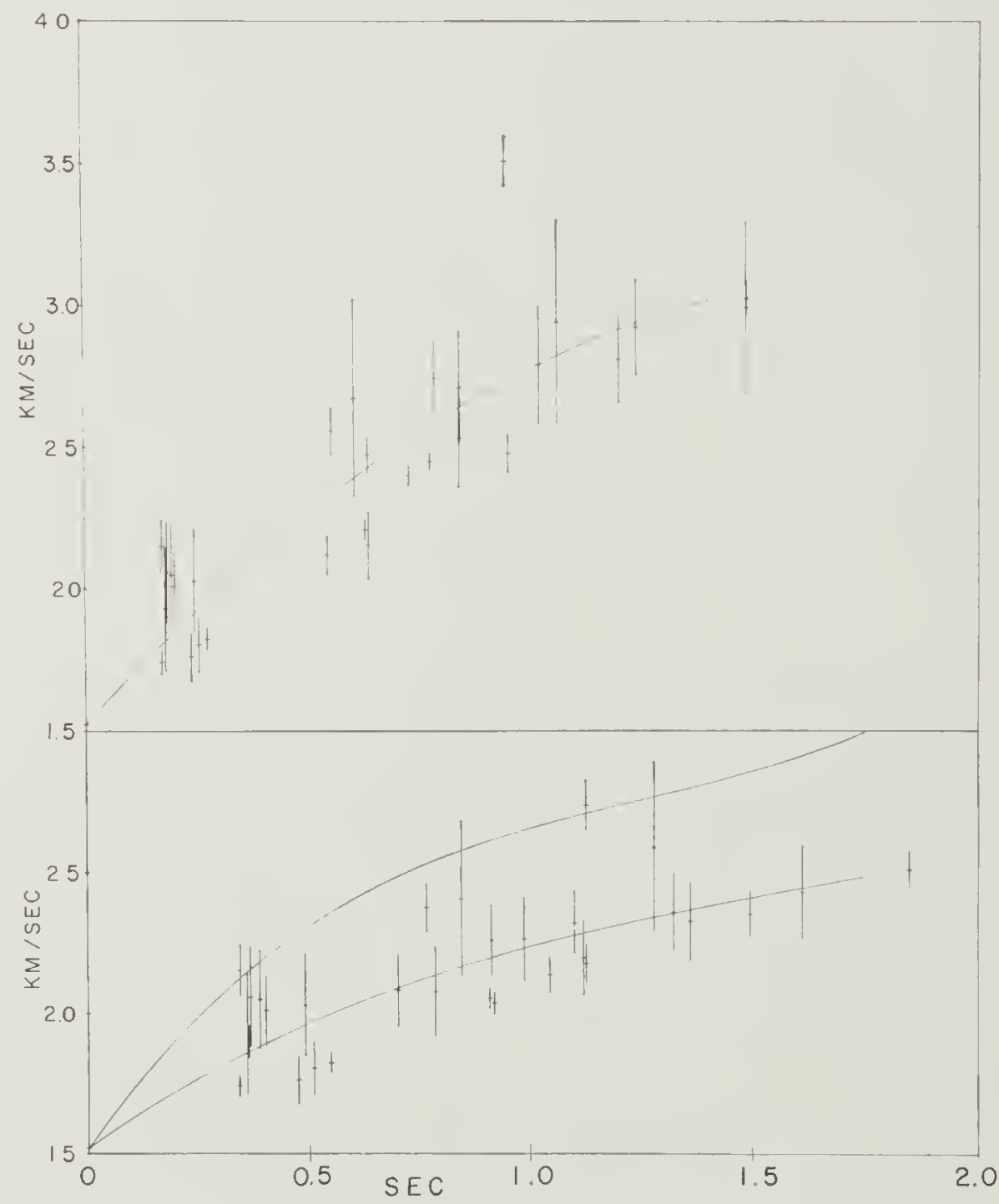

Fig. 14. (Upper curve) Instantaneous velocity curve derived from corrected interval velocities from the Gulf of Mexico. Interval velocities to which data were fitted are also plotted. Vertical bars represent twice the standard deviations. (Lower curves) Mean velocity curve and instantaneous velocity curve derived from it. Mean velocities to which the curve is fitted were derived from the same data as in the upper part of the figure. 
A useful check on the $T^{2} / \Lambda^{-2}$ solutions is occasionally provided by wide-angle reflection data. The slopes of these reflection curves generally give an estimate of the mean velocity within a layer (at horizontal distances that are large in comparison to layer thickness). The procedure is to measure the slope of the reflection curve at the greatest distance from the origin and to convert the slope to an apparent mean velocity. The method provides approximations that are evidently randomly in error by about $200 \mathrm{~m} / \mathrm{sec}$. Table 1 enables us to compare the apparent layer velocities determined in this way with the apparent layer velocities determined from $T^{2} / X^{2}$ solutions.

Regional velocity curves. The corrected velocity curve for the sediments in the Gulf of Mexico appears in the upper curve in Figure 14. The overburden on the high-speed refracting sediments in the gulf is constant in the region where our measurements were made. It is therefore possible to plot all the velocities without introducing the seatter observed in the Atlantic, where the high-speed layers occur at variable depths below the sea floor. This comparison leads to a generalized velocity curve that is surprisingly linear. V24-17 was the only station providing interval velocities from the Bay of Campeche, where the faster layers crop out. The third-layer solution at V24-17 is the anomalously ligh point $(3.51 \mathrm{~km} / \mathrm{sec})$ at about $1.0 \mathrm{sec}$ in Figure 14. A more meaningful analysis of the velocity data of the Gulf of Mexico awaits the identification of prominent reflectors from core data. Only three interval velocities are available from the high-speed refracting sediments. They include V24-17 (already discussed) and the two deepest solutions, which do not depart significantly from the generalized curve.

The corrected interval velocity curve for the Atlantic data is shown in the upper curve of Figure 15. Layer $\beta$ solutions and combinations of two layers have been eliminated from this plot. Station V23-17 from the Newfoundland ridge has been eliminated because the layers crop out on the ridge and cannot be identified. V22-2 from the Rio Grande rise occurs in shallow-water calcareous sediments, which cannot be classified with the other deep-water solutions, and has been eliminated. The Atlantic curve shows the same general features

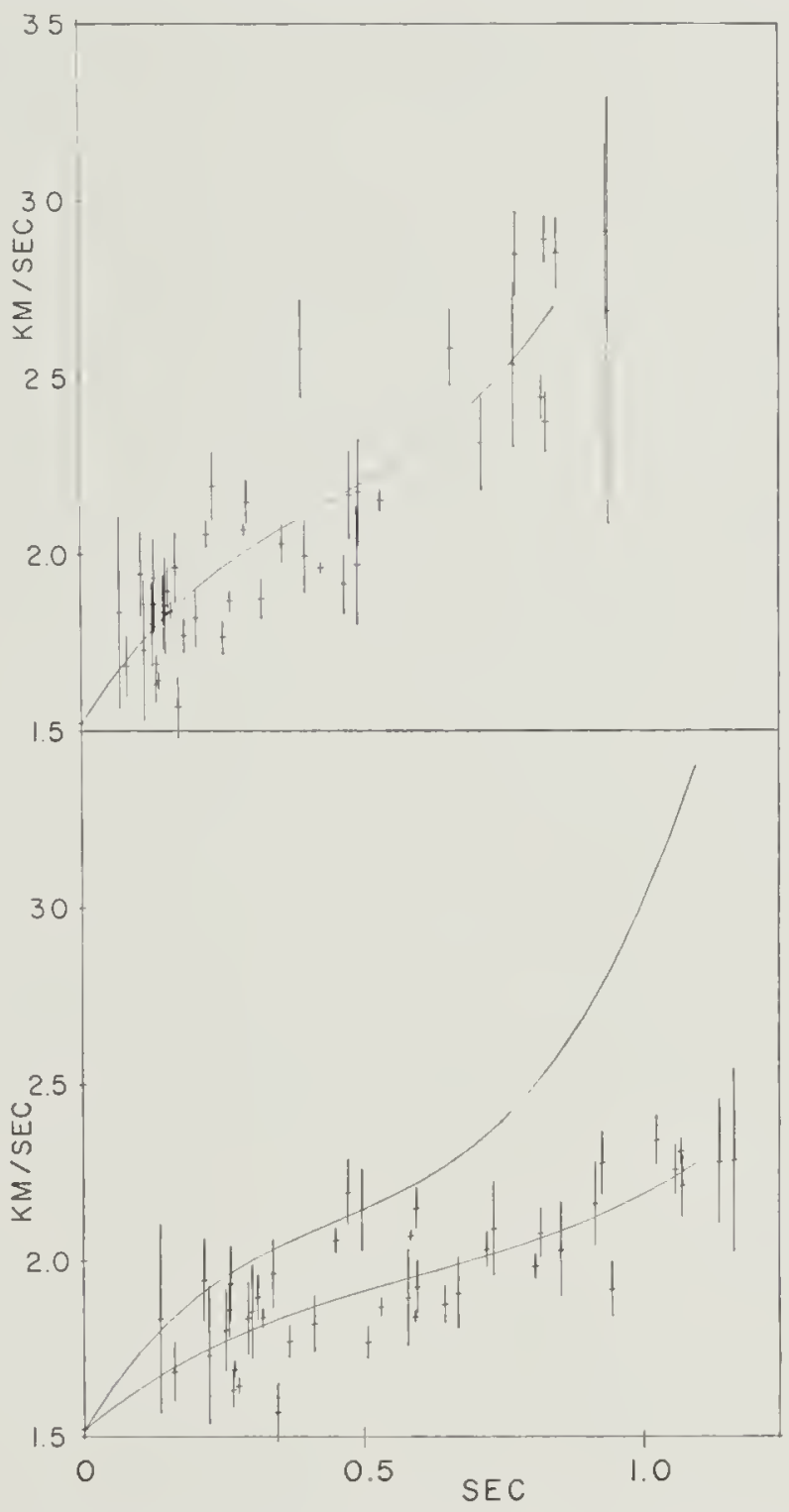

Fig. 15. (Upper curve) Instantaneous velocity curve derived from corrected interval velocities from the Atlantic. (Lower curves) Mean velocity curve and corresponding instantaneous velocity curve from the same data.

that the gulf curve does, except that the velocity gradient increases with depth at depths greater than about 0.5 sec because of lower velocities in the sediment layer above horizon A. This gradient is greater than the gradient observed at the water-sediment interface and seems unrealistic at a depth of about $2 \mathrm{~km}$.

The detailed velocity data now available show that the Grand Banks and Cape basin regions give relatively high velocities in the first layer. If these solutions are eliminated (see the upper curve of Figure 16), the scatter is reduced but the large gradient still occurs at depths. This 


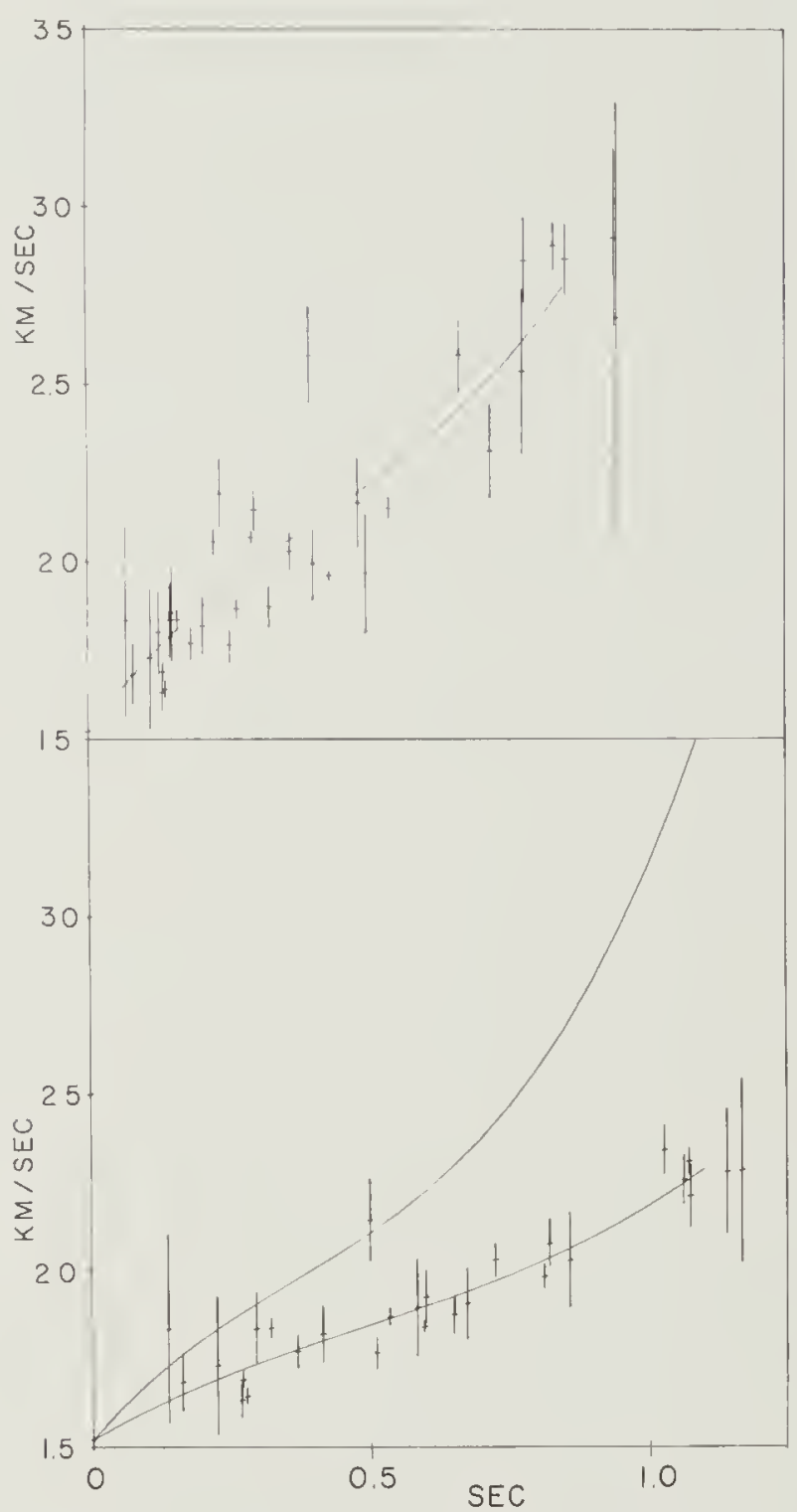

Fig. 16. (Upper curve) Instantaneous velocity curve derived from corrected interval velocities from the Atlantic (exclusive of Grand Banks and Cape basin solutions). (Lower curves) Mean velocity curve and corresponding instantaneous velocity curve from the same data.

leads to the suggestion that a genuine velocity discontinuity exists in the region of layer $\mathrm{A}$. Individual stations frequently reveal apparent velocity discontinuities at horizon $\mathrm{A}$ or at the next lower identifiable horizon within layer A (but still above horizon $\beta$ ). Selected stations from the Atlantic are plotted in Figure 17 to show that a large positive gradient has to be assumed within layer $\mathrm{A}$ if the velocity discontinuities (or velocity transition zones) are eliminated at these stations.
The effect of removing all layer A solutions from the data of Figure 16 is shown in the upper curve of Figure 18. We are now left with a curve that has no large gradients at depth. The velocity increase is nearly linear with vertical travel time, as suggested by the North Atlantic data of Houtz and Ewing [1963]. A comparison of Figure 14 with Figure 18 shows that there may be a significant difference between the shallow-layer solutions of the Gulf of Mexico and the Atlantic Ocean. The difference would become much greater if the gulf fit were based only on solutions that occur no deeper than those from the Atlantic. As it is, the gulf curve is depressed downward by the deeper solutions.

This difference could be due to the effects of deposition in a semiclosed basin, which may give rise to higher velocities in the gulf. The concepts of continental drift and sea-floor spreading suggest that the sediments of layer A could also have been deposited in a semiclosed basin. A surprisingly close relationship between the interval velocities of Atlantic layer

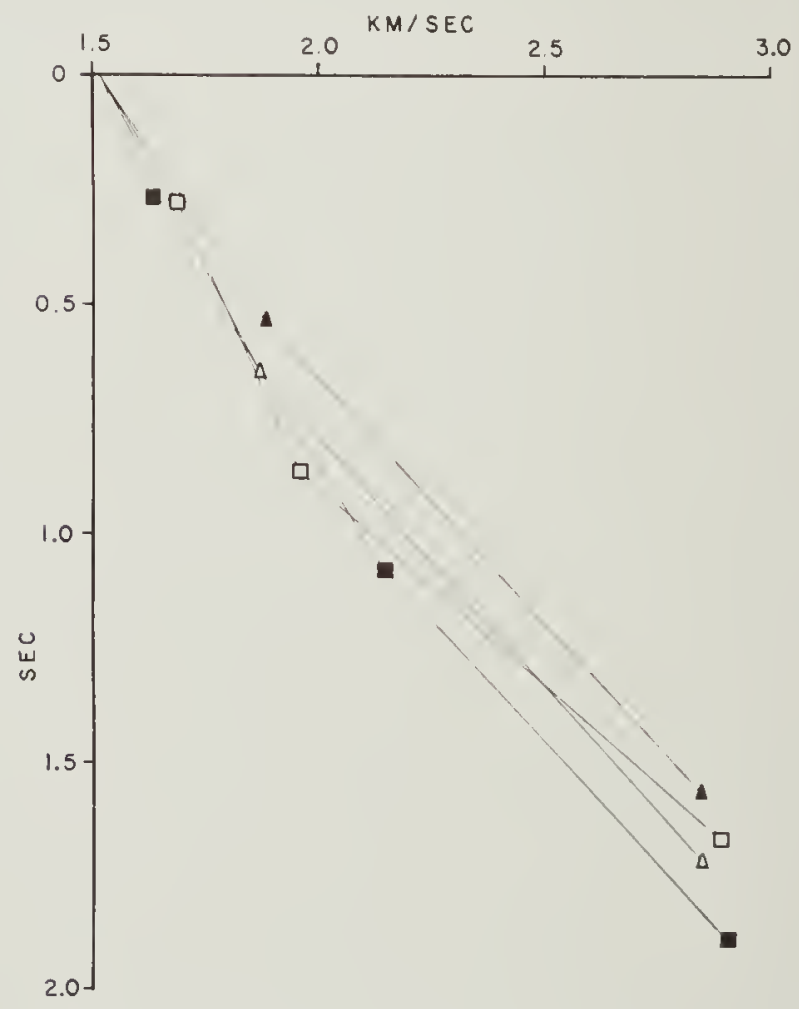

Fig. 17. Selected sonobuoy solutions requiring a velocity discontinuity (or transition zone) above the deepest layer. Solid square indicates data from V24-1; open square, V22-3; solid triangle, C11-1; open triangles, V23-49. 


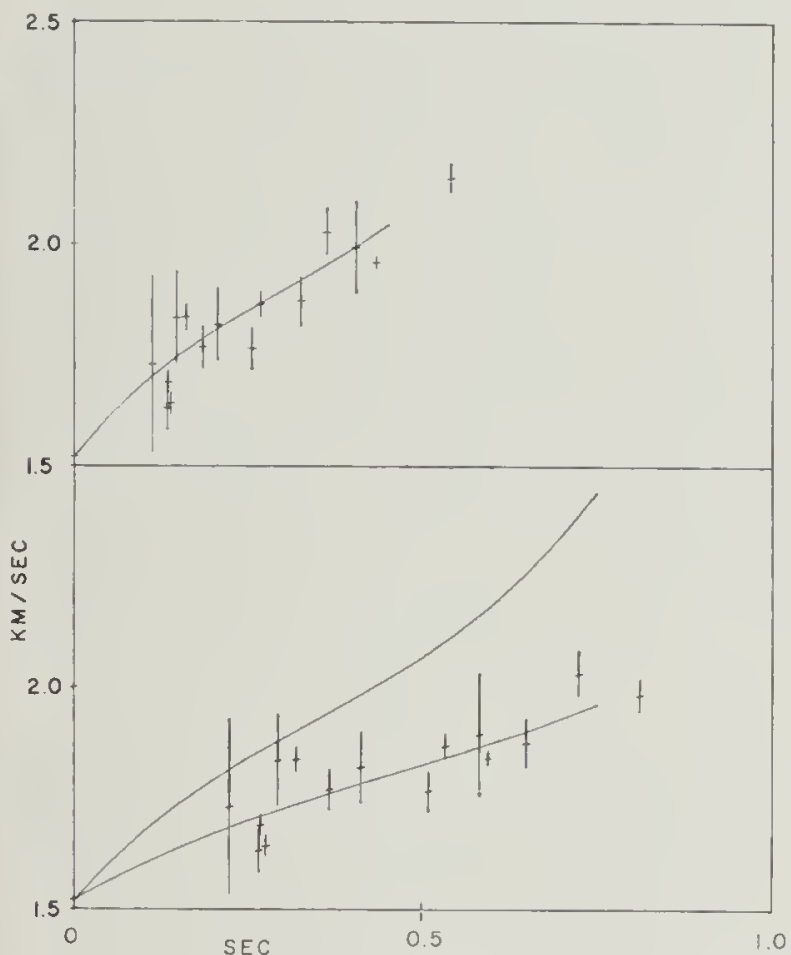

Fig. 18. (Upper curve) Instantaneous velocity curve derived from corrected interval velocities from the Atlantic (exclusive of layer A, Grand Banks, and Cape basin solutions). (Lower curve) Mean velocity curve and corresponding computed instantaneous velocity from the same data.
$A$ and the interval velocities of the gulf are shown in Figure 19, where the two types of velocity are combined in an interval velocity plot (not corrected). A similar plot of layer A velocities on the Tertiary Atlantic velocities (exclusive of the Grand Banks solutions) reveals an average mismatch of about $200 \mathrm{~m} / \mathrm{sec}$, which is most pronounced at the greater depths.

Although we have shown that the inclusion of layer A velocities introduces large velocity gradients at depth in the Atlantic, the effect is largely due to the four stations of Figure 17, which involve large thicknesses of sediment. The dominant pattern in the layer $A$ velocities is that they are influenced by overburden pressure, as are the Tertiary sediment velocities. In the same way, the gulf velocities are mostly controlled by overburden pressure. The major difference is in the shallow layers, which are faster in the Gulf of Mexico than in the Atlantic Ocean. Faster velocities occur in the Gulf of Mexico in spite of the fact that sedimentation rates in the gulf are at least an order of magnitude greater than they are in the Atlantic. The greater sedimentation rates should produce lower velocities in the gulf. The existence of

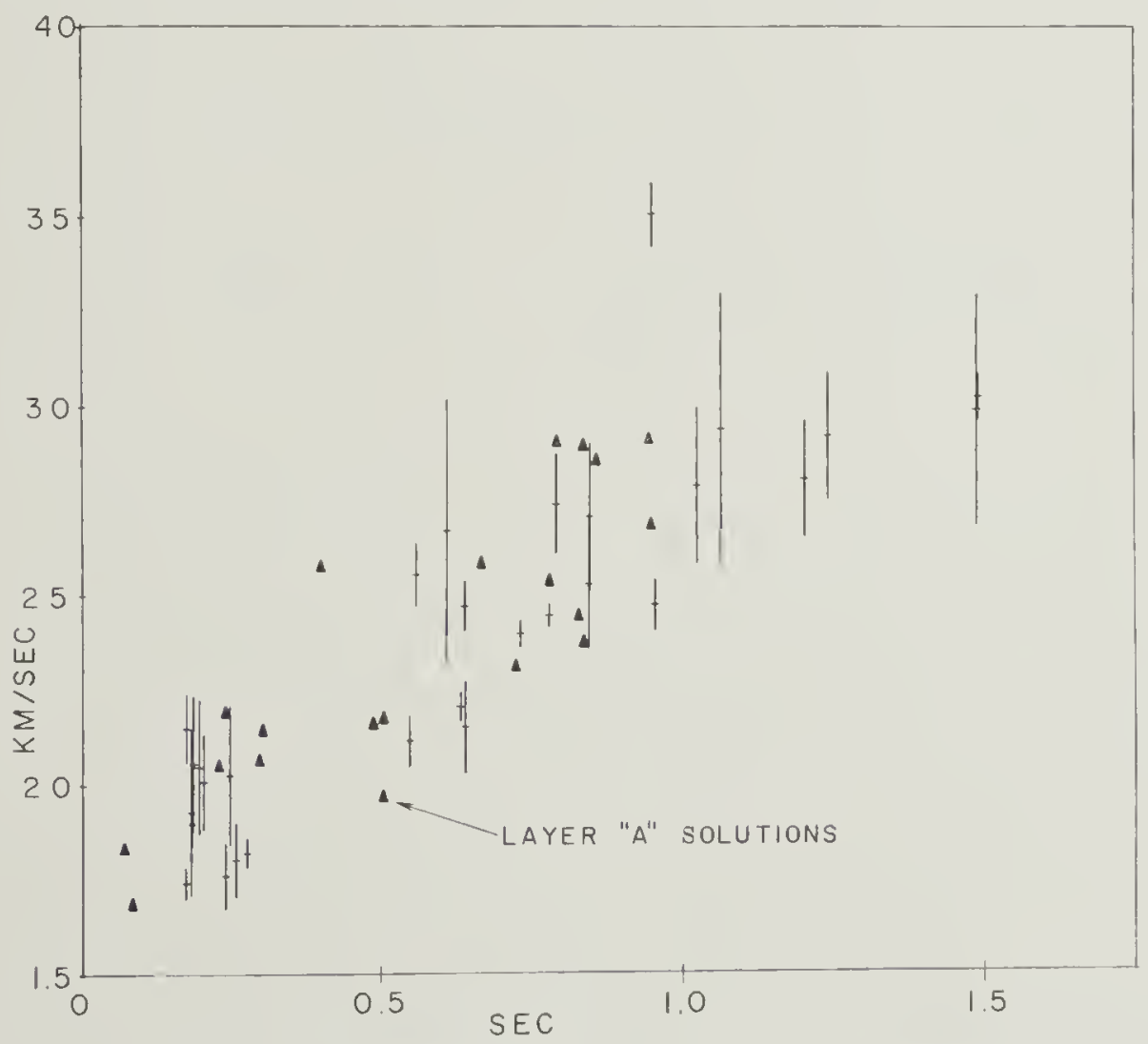

Fig. 19. Interval velocities from Atlantic, layer A, and all Gulf of Mexico solutions. 
high-speed shallow sediments in the gulf therefore requires an explanation that is independent of the rate of sedimentation.

Ewing et al. [1968] have shown that sedimentation in the South Atlantic is controlled by the massive movements of bottom currents that transport lutites (clay-sized particles) in suspension along the sea floor. The seawater near the floor carrying a relatively large amount of material in suspension is called the 'nepheloid layer.' Exwing et al. show that sedimentation of this type began when horizon A was deposited and that it has continued to deposit in this manner to the present time. Nepheloid deposition, under the influence of deep-sea currents, controls the distribution of Tertiary sediments in the North Atlantic, except in the areas in which turbidites make significant contributions, as they do in the Grand Banks area, where the velocities are high and the profiles show densely layered (turbidite) sediments. The massive circulation of lutites does not occur in the Gulf of Mexico, where the sedimentation is in a semiclosed basin. As a result, homogeneous low-velocity sediments are absent in the gulf and the sediment velocities are therefore greater than sediment velocities in the Atlantic.
Mean velocity curves for the Gulf of Mexico and the Atlantic Ocean appear as the lower curves in Figures 14, 15, 16, and 18. The curves represent polynomials of the type $\bar{V}=A+B T+$ $C T^{2}+D T^{2}$, where $T$ is the one-way vertical travel time within the sediments. The coefficients $A, B, C$, and $\mathrm{D}$ and the standard deviation of the fit are given in Table 2. Instantaneous velocity curves are plotted with the mean curves. They have been derived from the mean velocity equation by differentiating the expression for the sediment thickness, $H=A T+B T^{2}+C T^{3}+$ $D T^{4}$. That is,

$$
V=\frac{d H}{d T}=A+2 B T+3 C T^{2}+4 D T^{3}
$$

It can be seen from the figures that curves found in this way depart significantly from the instantaneous velocity curves derived from observed interval velocities, especially at the greater depths. The difference is due to errors introduced by the indirect determination.

Previous work on the distribution of deepsea sediment velocities was not based strictly on the identification of stratigraphic horizons. This shortcoming has occasionally led to generalized curves that take no account of the ve-

TABLE 2. Velocity-Depth Functions

\begin{tabular}{|c|c|c|c|c|c|c|c|c|}
\hline & \multicolumn{4}{|c|}{ Cocfficients of Polynomials } & \multirow{2}{*}{$\begin{array}{l}\text { Std. } \\
\text { Dev., } \\
\mathrm{m} / \mathrm{sec}\end{array}$} & \multirow{2}{*}{$\begin{array}{l}\text { Telocity } \\
\text { Ave., } \\
\sec ^{-1}\end{array}$} & \multirow{2}{*}{$\begin{array}{c}\text { Gradients } \\
\text { at } \\
T^{\prime}=0 \\
\sec ^{-1}\end{array}$} & \multirow{2}{*}{$\begin{array}{c}\text { Depth } \\
\text { Range of } \\
\text { Ave. } \\
\text { Gradient, } \\
\text { m }\end{array}$} \\
\hline & $A$ & $B$ & $C$ & $D$ & & & & \\
\hline \multicolumn{9}{|l|}{ Gulf of } \\
\hline Mexico & $1.5207^{*}$ & $1.7241^{*}$ & $-0.4679^{*}$ & $-0.0002^{*}$ & 217 & 0.87 & 1.13 & 543 \\
\hline $\begin{array}{l}\text { (Fig. 15) } \\
\text { Atlantic }\end{array}$ & $1.5202^{*}$ & $2.5092^{*}$ & $-3.7478^{*}$ & $2.8531^{*}$ & 160 & 0.91 & 1.65 & 540 \\
\hline $\begin{array}{l}\text { Atlantic } \\
\text { (Fig. 16) } \\
\text { Atlantic }\end{array}$ & $1.5201^{*}$ & $2.1785^{*}$ & $-2.6577^{*}$ & $2.1528^{*}$ & 150 & 0.90 & 1.43 & 525 \\
\hline $\begin{array}{l}\text { (Fig. 18) } \\
\text { Gulf of }\end{array}$ & $1.5199^{*}$ & $1.962 S^{*}$ & $-3.4692^{*}$ & $3.7864^{*}$ & 61 & 0.73 & 1.29 & 519 \\
\hline $\begin{array}{l}\text { Mexico } \\
\text { Atlantic }\end{array}$ & $1.5202 \dagger$ & $1.1072 \dagger$ & $-0.4906 \dagger$ & $0.0983 \dagger$ & 163 & & & \\
\hline $\begin{array}{l}\text { (Fig. 15) } \\
\text { Atlantic }\end{array}$ & $1.5200 \dagger$ & $1.3001 \dagger$ & $-1.4287 \dagger$ & $0.7902 \dagger$ & 122 & & & \\
\hline $\begin{array}{l}\text { (Fig. 16) } \\
\text { Atlantic }\end{array}$ & $1.5201 \dagger$ & $0.9180 \dagger$ & $-0.8085 \dagger$ & $0.5523 \dagger$ & 81 & & & \\
\hline (Fig. 18) & $1.5199 \dagger$ & $0.8895 \dagger$ & $-0.8781 \dagger$ & $0.6318 \dagger$ & 60 & & & \\
\hline
\end{tabular}

* Used to fit corrected interval velocity (instantaneous velocity).

$\dagger$ Used to fit mean velocities. 
locity discontinuities that occur within layer $\mathrm{A}$ and at horizon $\beta$. Generalized curves cannot truly represent the complexity of the consolidation process. The velocity curve of Figure 18 (unconsolidated sediments from the Atlantic) has been converted to a depth-dependent curve and is plotted with some of the previous work in Figure 20. The comparison shows a fair agreement with the curves of Houtz and Ewing $[1963,1964]$, whose plots were also constrained to pass through $1.52 \mathrm{~km} / \mathrm{sec}$ at $h=0$. Their work was based on an attempt to eliminate consolidated sediments by excluding layers that propagated critical refractions. The data of Nafe and Drake [1963] were based on 'refraction' velocities before it was realized that the upper layers of deep-sea sediments ordinarily produce wide-angle reflections but not refractions [Houtz and Ewing, 1963]. According to our data, the Nafe and Drake curve is about $0.2 \mathrm{~km} / \mathrm{sec}$ too fast for the Atlantic, so that at most depths in the unconsolidated sediments the density based on our fit will be about $0.1 \mathrm{~g} / \mathrm{cm}^{8}$ less. Their curve, however, works quite well in the Gulf of Mexico. The Knox [1965] curve represents the velocity distribution of all the sediments at a specific, closely studied site.

Velocity gradients. Velocity gradients are usually measured in units of $\mathrm{sec}^{-1}$, which are not directly measurable from polynomial equations in time. To express the gradient in the usual manner, we see that if

$$
V=\frac{d h}{d t}=A+B T+C T^{2}+D T^{3}
$$

Gradient $\left(\sec ^{-1}\right)$

$$
=\frac{d V}{d h}=\frac{B+2 C T+3 D T^{2}}{A+B T+C T^{2}+D T^{3}}
$$

which expresses the instantaneous gradient. The work of Houtz and Ewing [1964] suggested that the gradient at the water-sediment interface, based on an $R_{\&}-R_{1}$ analysis of curved ray arrivals [Ewing and $\mathrm{Nafe}, 1963$ ], was between 1.5 and $2.0 \mathrm{sec}^{-1}$. By means of equation 2 we see that, at $T=0$, the gradient is simply $B / A$. The present work yields water-sediment interface gradients ranging from 1.1 to $1.7 \mathrm{sec}^{-1}$, a surprisingly close agreement when the lack of precision is considered.

Houtz and Ewing determined an average gradient of $1.0 \mathrm{sec}^{-1}$ down to depths of about

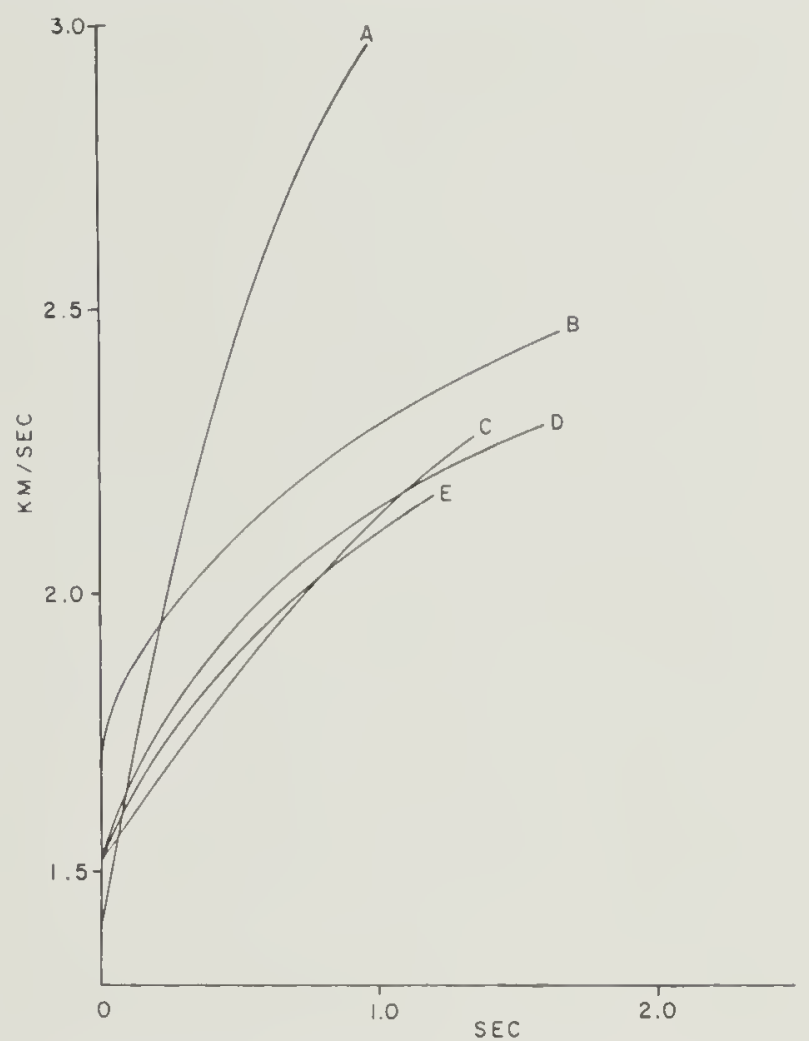

Fig. 20. Comparison of published velocity curves with the present work (from the data of Figure 18). Curve A from Knox [1965]; B, Nafe and Drake [1961]; C, Houtz and Ewing [1963]; D, Houtz and Ewing [1964]; E, present work.

500 meters. Hamilton [1965] measured velocities at depth in deep-sea sediments from the cores at the experimental Mohole site, Guadelupe Island. His results yielded a gradient of about $1.0 \mathrm{sec}^{-1}$ in the unconsolidated sediments.

The average gradient $\langle d v / d h\rangle$ can be found by integration over a given depth range using

$$
\langle d v / d h\rangle=\left(v-v_{0}\right) / h
$$

and depends only on the initial and terminal velocities. The average gradients to a depth of about 500 meters in the present study range from 0.73 to $0.91 \mathrm{sec}^{-1}$. The average gradients to a depth of about 500 meters and the gradients at the water-sediment interface are tabulated in Table 2. The small differences between the average and the interface gradients suggest that little curvature has been introduced by constraining the fit to pass through $1.52 \mathrm{~km} / \mathrm{sec}$ at $T=0$.

\section{Summary}

Velocity solutions from sonobuoy data have been correlated with the reflecting horizons ob- 
served in the vertical profiler data. Three major sequences have been identified in the Atlantic sediments:

1. Unconsolidated Tertiary sediments, layered to varying degrees, whose velocity increases rather uniformly with depth. Their velocities range from about 1.6 to $2.2 \mathrm{~km} / \mathrm{sec}$.

2. Semiconsolidated Upper Cretaceous sediments whose velocity increascs somewhat discontinuously with depth (with local variations). The main body of sediments is homogeneous but is capped by a thin zone of denscly layered material. Their velocities range from 1.7 to 2.9 $\mathrm{km} / \mathrm{sec}$.

3. Consolidated sediments of Lower Cretaceous age (and perhaps older) whose velocity is relatively constant and independent of overburden thickness. The sequence is weakly layered, and interval velocities range from 2.7 to $3.7 \mathrm{~km} / \mathrm{sec}$.

Sonobuoy and other data show that layer $\beta$ (except for local occurrences), as far as we know, is missing in the South Atlantic. This suggests that parts of the North Atlantic, where this layer is widely observed, are older. Sediment origin in the two oceans is quite dissimilar, however, and the acoustic differences may not imply age differences.

Gulf of Mexico sediment velocities cannot be analyzed on the basis of dated reflectors, owing to a lack of outcrops. A velocity structure exists in the gulf that is essentially controlled by overburden, and the increase of velocity with overburden is similar to the increases in the Atlantic.

Some velocity variability $(200$ to $300 \mathrm{~m} / \mathrm{sec}$ ) occurs in the upper layers of sediment. The slower velocities in this range seem to be associated with lutites deposited by the nepheloid layer under the influence of relatively swift deep-sea currents, e.g., in the western South Atlantic and throughout most of the North Atlantic abyssal plains and rise. The faster sediment velocities occur in regions of weaker bottom water currents (Gulf of Mexico) or in regions where thick turbidites occur (Grand Banks area). The sediments of layer A may have been deposited when the Atlantic basins were not as open to circulation as they now are and when there was not strong deep water circulation.

Velocity analysis also shows that a relatively profound clange occurred after layer $\beta$ was deposited. This observation applies only to four good determinations, however, all of which are in the relatively small area between the Bahama Islands and the Blake-Bahama outer ridge. The complete lack of significant velocity reversals points up the remarkably uniform properties of consolidation, which in spite of regional differences in sediment types, conditions of deposition, provenance, and water depth yields quite similar velocity-depth curves.

\section{APPENDIX 1}

The basic ray theory of seismic reflection and refraction requires that a refraction line represents the velocity at the upper interface of a horizontal layer. The refraction line is tangent to the reflection hyperbola for this interface at the critical distance. At large distances from the source, however, reflections from the lower interface of the refracting layer will become indistinguishable from the refracted waves. This follows from the geometry of rays in thin layers with a constant velocity, because the travel-time difference along the upper interface and the single internal reflection is very small. As a typical example, the difference in travel times in a layer 200 meters thick of $3.0-\mathrm{km} / \mathrm{sec}$ material will be about $0.004 \mathrm{sec}$ at a distance of $2 \mathrm{~km}$ from the critical distance. The sonobuoy refraction data are based on waves with a period of $0.05 \mathrm{sec}$, an order of magnitude greater than the time difference we would like to resolve in our typical example.

Owing to interference effects of thin layers, the refracted arrivals are often shingled, so that at greater distances the initial part of the wave disappears. We cannot claim accuracy in the tangent points determined from our data beyond one cycle $(0.05 \mathrm{sec}$ or 125 meters of $5-\mathrm{km} / \mathrm{sec}$ material). These remarks seem to rule out any meaningful statements on refractions from thin sedimentary layers. A further disturbing effect is caused by critically refracted shear waves from the upper interface of basement. These arrivals will be tangent to the basement reflection curve and will show a velocity of about $3.0 \mathrm{~km} / \mathrm{sec}$, which is in the range of velocities atrributed to layer $\beta$.

Reflections often show an abrupt diminution of amplitude when critical reflection is reached at some shallower interface [Houtz and Ewing, 
1963]. Cut-off of this kind is best observed on oscillograms, which were not made for the sonobuoy data described here.

Although not closely related to the present work, the behavior of critically refracted shear waves may be explained on the basis of the sonobuoy results. These results show where high-speed sediments exist in the deep sea. Without knowledge of the extent of these highspeed sediments, the amplitudes and frequency of occurrence of shear waves are perplexing if relatively uniform sediments are assumed to exist down to the basement interface.

Houtz [1965] studied shear wave amplitudes of critical refractions ( $P S P$ type) from deep-sea crustal layers. Unpublished parts of the Houtz work showed that shear waves from the oceanic layer were not recorded where a thick sedimentray cover occurred. This was thought to be due to higher sediment velocities at the sediment-basement interface, where the conversion from $P$ to $S V$ occurs. The resulting increase in the sediment-basement velocity ratio would decrease the shear wave amplitude. Hence, the shear wave energy available to propagate along the oceanic interface is reduced. The data of that study appear in Figure 21, which is a histogram showing that shear waves are not observed when the sediment-basement velocity ratio reaches the region of 0.42 . For a typical basement this value corresponds to a sediment velocity of about $2.1 \mathrm{~km} / \mathrm{sec}$.

It may be significant that the highest velocities recorded in the unconsolidated sediments of the Atlantic Ocean do not exceed about 2.2 $\mathrm{km} / \mathrm{sec}$. (See Figure 18.) This suggests that shear waves are not recorded where the highspeed sediments, which occur below layer A, are present. The amplitude of $P S P$ from the oceanic layer diminishes to nearly one-sixth its original value if a $3.0-\mathrm{km} / \mathrm{sec}$ layer is introduced between a $2.0-$ and $5.0-\mathrm{km} / \mathrm{sec}$ interface. This seems to be an adequate explanation for the observed behavior.

The existence of high-speed sediments in the deep sea also explains the scarcity of critically refracted $S$ waves from the basement layer, compared with those from the oceanic layer. If Poisson's ratio is 0.25 in the basement layer, the shear wave velocity will range from 2.6 to $3.2 \mathrm{~km} / \mathrm{sec}$, corresponding to basement $P$ wave velocities of 4.5 to $5.5 \mathrm{~km} / \mathrm{sec}$. Clearly, no basement shear wave can occur (or can occur only at great distances from the source) where sediment velocities are about $3.0 \mathrm{~km} / \mathrm{sec}$.

\section{APPENDIX 2}

If $T$ is the one-way reflection time below the surface of the sediments, $V_{\Delta T}$ is the interval velocity from $T$ to $T+\Delta T$, and $V$ is the instantaneous velocity, then

$$
V_{\Delta T}=\frac{1}{\Delta T} \int_{T}^{T+\Delta T} V(T) \cdot d T
$$

This interval velocity is assigned to time $T+$ $(\Delta T / 2)$ where the real instantaneous velocity

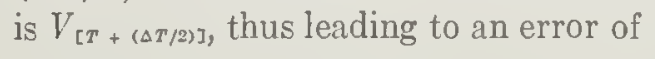

$$
\epsilon=V_{\Delta T}-V_{[T+(\Delta T / 2)]}
$$

If $V=A+B T+C T^{2}$, then

$$
\begin{aligned}
V_{\Delta T}=C T^{2}+C T \Delta T & +C \frac{\Delta T^{2}}{3} \\
& +A+B\left(T+\frac{\Delta T}{2}\right)
\end{aligned}
$$

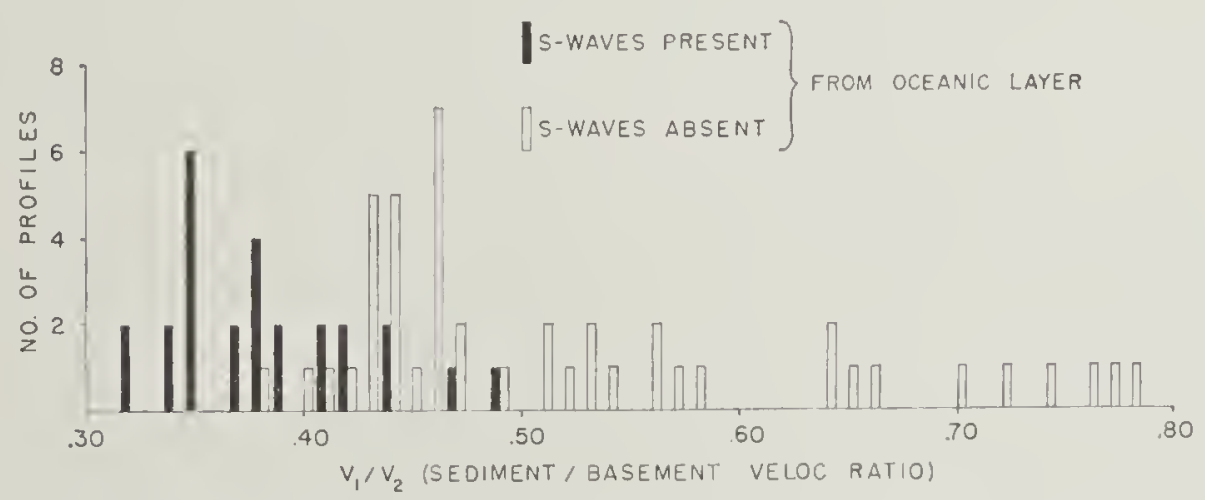

Fig. 21. Frequency of occurrence of shear waves in the North Atlantic as a function of the ratio of the sediment-basement interface velocities. 
whereas

$$
\begin{aligned}
V_{i T+(\Delta T / 2)\}}+A+B\left(T+\frac{\Delta T}{2}\right) & =C T^{2} \\
& +C T \Delta T+C \frac{\Delta T^{2}}{4}
\end{aligned}
$$

Thus, the error made in this assumption is

$$
\epsilon=V_{\Delta T}-V_{\{T+(\Delta T / 2)\}}=C \Delta T^{2} / 12
$$

The error is entirely due to the curvature term and in this case is independent of the depth (in time) within the sediments.

Similarly, it can be shown that for any polynomial expression of $V$, the errors introduced in the term of order $n\left(A T^{n}\right)$ are

$$
\begin{array}{r}
A \sum_{k=1}^{n+1} n ! T^{n-k+1} \Delta T^{k-1} /(n+1-k) !(k-1) ! \\
\cdot\left(1 / k-1 / 2^{k-1}\right)
\end{array}
$$

In particular, for the third-order polynomial used in this report

$$
\begin{gathered}
V=A+B T+C T^{2}+D T^{3} \\
\epsilon=\frac{1}{12} C \Delta T^{2}+\frac{1}{12}\left(3 D \cdot T \cdot \Delta T^{2}\right)+\frac{1}{8}\left(D \cdot \Delta T^{3}\right)
\end{gathered}
$$

Using the coefficients for the polynomials given in this report, we can show that the error made by assigning the interval velocity to time $T+$ $(\Delta T / 2)$ rarely exceed $50 \mathrm{~m} / \mathrm{sec}$ and generally is much less. This error is not critical, as it is generally less than the error in measurement, and it is easy to take it into account by the iterative procedure described in the report. In view of the small magnitude of the error involved in this approximation, it is much better to fit the velocity curve directly to the interval velocities rather than to the average velocities. The derivation of the instantaneous velocity curve from the average velocity curve will generally involve larger errors than the errors due to the interval velocity approximation.

Although our conclusion could have been reached intuitively, apparently it was not realized by $K$ nox [1965] in his criticisin of our use of such an approach.

Acknowledgments. This work has been supported by contracts with the U.S. Navy Office of Naval Research and Naval Ship Systems Command (N00024-67-C-1186), and by grants from the National Science Foundation. The work obviously would not have been possible without the sonobuoys and receivers and the assistance and cooperation of R. Stevens (ONR, New York), Mr. William J. Symonovicz, and Lt. Com. A. E. Steinman (both of Naval Air Systems Command) in procuring this equipment, which is gratefully acknowledged. Helpful discussions were held during the early stages of the work with members of the staff of the Hazeltine Corporation and of Sanders Associates, both of whom supply sonobuoys to the Navy. The assistance of many coworkers at Lamont Geological observatory is greatly appreciated, particularly the assistance of M. Ewing, J. L. Worzel, C. Windisch, G. Bryan, T. Aitken, W. Ludwig, H. Van Santford, A. C. Hubbard, and S. Gerber. We also express appreciation to the members of the technical staff at N.A.D.C. Johnsville, Pennsylvania, who have provided maintenance on the receivers. Discussions with J. E. Nafe were useful. G. Bryan and J. E. Nafe critically read the manuscript.

\section{REFERENCES}

Antoine, J., and J. Ewing, Seismic refraction measurements on the margins of the Gulf of Mexico, J. Geophys. Res., 69(7), 1975, 1963.

Bunce, E., and D. Fahlquist, Geophysical investigation of the Puerto Rico trench and outer ridge, J. Geophys. Res., 67 (10), 3955, 1962.

Ewing, J., J. Antoine, and M. Ewing, Geophysical measurements in the western Caribbean Sea and in the Gulf of Mexico, J. Geophys. Res., 65(12), 4087, 1960.

Ewing, J., J. Worzel, and M. Ewing, Sediments and structural history of the Gulf of Mexico, J. Geophys. Res., 67 (6), 2509, 1962.

Ewing, J., and J. Nafe, The unconsolidated sediments, in The Sea, edited by M. N. Hill, pp. 73-82, John Wiley \& Sons, New York, 1963.

Ewing, J., J. Worzel, M. Ewing, and C. Windisch, Ages of horizon A and the oldest Atlantic sediments, Science, 154(3753), 1125.1966.

Ewing, M., W. Ludwig, and J. Ewing, Sediment distribution in the oceans: The Argentine basin, J. Geophys. Res., 69(10), 2003, 1964.

Ewing, M., S. Eittreim, J. Ewing, and X. Le Pichon, Sediment transport and distribution in the Argentine basin, 3, Nepheloid layer and processes of sedimentation, in preparation, 1968.

Hamilton, E., Sound speed and related physical properties of sediments from experimental Mohole (Guadalupe site), Geophysics, 30(2), 257. 1965.

Houtz, R., and J. Ewing, Detailed sedimentary velocities from seismic refraction profiles in the western North Atlantic, J. Geophys. Res., 68(1S), 5233, 1963.

Houtz, R., and J. Ewing, Sedimentary relocities of the western North Atlantic margin, Bull. Seismol. Soc. Am., 54(3), S67, 1964.

Houtz, R., Amplitude ratios of certain arrivals in deep-sea refraction records (abstract), Trans. Am. Geophys. Union, 46(1), 103, 1965. 
King, L., Morphology of the Earth, 577 pp., Hafner, New York, 1962.

Innox, W., A deep-ocean sedimentary velocity function, J. Geophys. Res., 70(8), 1999, 1965.

Le Pichon, X. J. Ewing, and R. Houtz, Deep sea sediment velocity determination while reflection profiling, J. Geophys. Res., 73(8), 1968.

Nafe, J., and C. Drake, Physical properties of marine sediments, in The Sea, edited by M. N. Hill, pp. 794-\$28, John Wiley \& Sons, New York, 1963.

Northrop, J., and M. Ransone, Some seismic profiles near the western end of the Puerto Rico trench, J. Gen. Physiol., 45(4), 243, 1962.
Saito, T., L. Burckle, and M. Ewing, Lithology and paleontology of the reflective layer horizon A, Science, 154(3753), 1173, 1966.

Savit, C., W. Knox, D. Blue, and L. Paitson, Reflection and velocity profiles at the outer ridge, Puerto Rico, J. Geophys. Res., 64(4), 701, 1964. Schreiber, B. C., Core, sound velocimeter, hydrographic and bottom photographic stations-cores, Area I, vol. 8C, U.S. Naval Oceanographic Office, 1966.

(Received August 14, 1967 ; revised November 2, 1967.) 



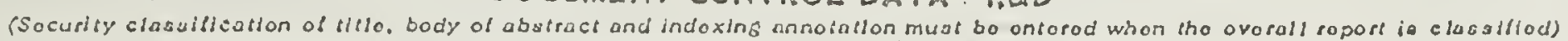

1. ORIGINATING ACTIVITY (Comorato outhor)

Lamont Geological Observatory

Columbia University

Palisades, Ner York 10964

20. AEPOAT SECUAITY CLABSIFICATION

Unclassified.

3. REPCRT TITLE

VETOCITY OE DEIP-SEA SEDINUNAS FROM SOTOBUOY DATA

\section{DESCRIPTIVE NOTES (TYPo of roport and inciualve doroo)}

Technical Report

\section{AUTHORis) (Laol name, (trot namo, Iniliab)}

Robert Houtz, John Ewing and Kavier Le Pichon

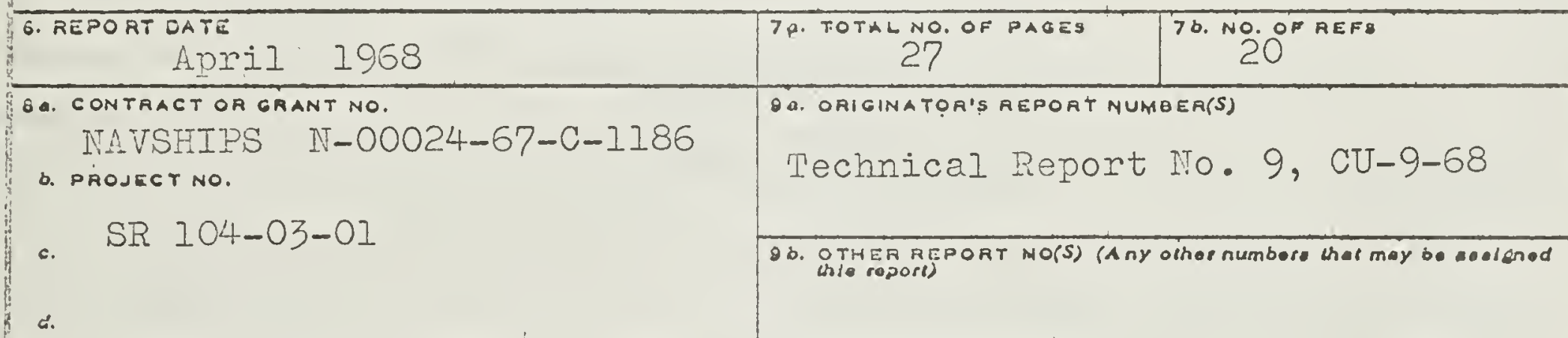

10. AVAILABILITY/LIMITATION NOTICES

Distribution of this document is unlimited

\begin{tabular}{|c|c|}
\hline 11. SUPPLEMENTARY NOTES & $\begin{array}{l}\text { 12. SPONSORING MILITARY ACTIVITY } \\
\text { Department OI the Navy } \\
\text { NAVSHIPS } \\
\text { IJashington, D.C. }\end{array}$ \\
\hline
\end{tabular}

\section{ABSTRACT}

Interval velocity solutions from sonobuoy data reveal three major sedimentary sequences: (I) Unconsolidated sediments whose velocity increases with depth of burial and ranges from 1.6 to 2.2 $\mathrm{lm} / \mathrm{sec} ;$ (2) semiconsolidated sediments (layer 1 ), which probably have some velocity discontinuities, whose velocity increases with depth of burial and ranges from 1.7 to $2.9 \mathrm{~km} / \mathrm{sec} ;$ (3) consolidated sediments (layer 6 ), measured in a few places, whose velocity is apperently independent of overburden and ranges from 2.7 to $3.7 \mathrm{~km} / \mathrm{sec}$. 
Security Clessification

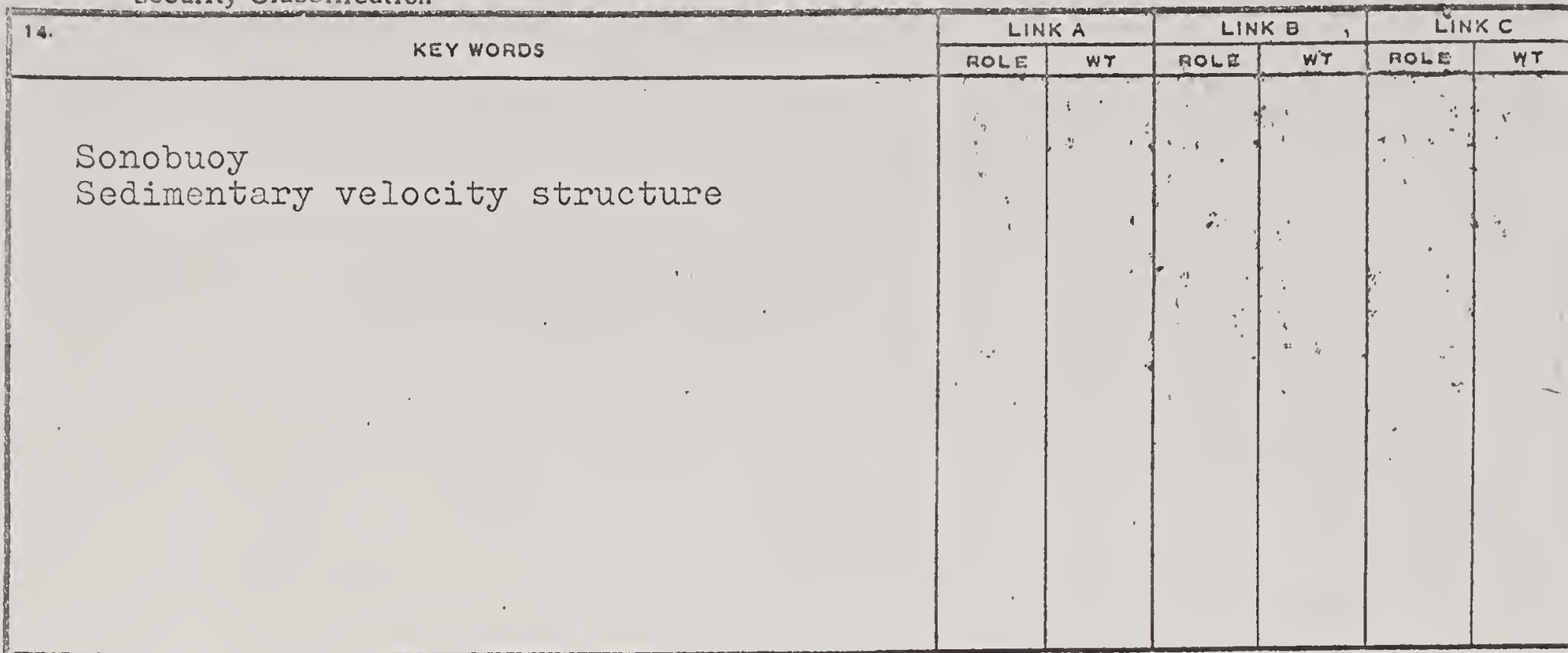

\section{INSTRUCTIONS}

1. ORIGINATTNG ACTIVITY: Enter the name and addresa of the contractor, aubconiractor, grantee, Department of Defense activity or other orgnnization (corporate author) issuing the report.

2a. REPORT SECURTY CLASSIFICATION: Enter the overall security classification of the report. Indic ate whether "Restricted Data" is included Marking is to be in accord ance with appropriate security regulations.

2b. GROUP: Automatic downgrading is specified in DOD Dlrective 5200.10 and Armed Forces Industrial Manual. Enter the group number. Also, when applicable, show that optional markings have been us ed for Group 3 and Group 4 as authorized.

3. REPORT TITLE: Ente: the complete report title in all capital letters. Titles in all cases should be unclassified. If a meaningiul title cannot be selected without classification, show title classification in all capitals in parenthesis immediately following the title.

4. DESCRIPTIVE NOTES: If appropriate, enter the type of revort, e.g., interim, progress, summary, annual, or final.

Give the inclusive dates when a specific reporting period is covered.

5. AUTHOR(S): Enter the name(s) of author(s) as shown on or in the report. Enter last name, first name, middle initial. If rilitary, show rank nd branch of service. The name of the principal dithor is an absolute minimum requirement.

6. REPORT DATE: Enter the date of the report as dny, month, year, or month, year. If more than one date appeara on the report, uae date of publication.

7a. TOTAL NUMBER OF PAGES: The total page count shouid follow normal pagination procedures, $i_{\text {r }} e_{\text {, }}$ enter the number of pages containing information

7b. NUMBER OF REFERENCES: Enter the total number of references cited in the report.

8a. CONTRACT OR GRANT NUMBER: If appropriate, entet the applicable number of the contract or grant under which the report $w$ as written

8b, 8c, \& 8d. PROJECT NUMBER: Enter the appropriate military department identification, such as project number, subproject number, system numbers, task number, etc.

9a. ORIGINATOR'S REPORT NUMBER(S): Enter the officlal report number by which the document will be identified and controlled by the originating activity. Thla number muat be unique to this report.

9b. OTHER REPORT NUMBER(S): If the report has been as or by the sponsor), also enter this number(s).

10. AVAILABILITY/LIMITATION NOTICES: Enter any limitations on further dissemination of the report, other than thoae imposed by aecurity classification, using etandard statements auch as:

(1) "Quallfied requestera may obtain copies of thia report from DDC."

(2) "Foreign announcement and dissemination of this report by DDG is not authorized."

(3) "U. S. Government agenciea may obtain copiea of this report directly from DDC. Other qualified DDC users shall request through

(4) "U. S. military agencles may obtain copiea of this report directly from DDC. Other qualified users shall request through

(5) "All distribution of this report ia controlled Qualified DDC users shall request through $+\infty$

If the report has been furnished to the Office of Technical Services, Department of Commerce, for sale to the public, indicate this fact and enter the price, if known

11. SUPPLEMENTARY NOTES: Use for additional explanatory notes.

12. SPONSORING MILITARY ACTIVITY: Enter the name of the departmental project office or laboratory sponsoring (par ing for) the research and development. Include address.

13. ABSTRACT: Enter an abstract giving a brief and factual summary of the document indicative of the report, even though it may also appear elsewhere in the body of the technical re. port. If additional space is required, a continuation sheet shall be attnched.

It is highly desirable that the abstract of classified reports be unclassified. Each paragraph of the abstract shall end with an indication of the military security classification of the information in the paragraph, represented as (TS). (S). (C), or (U).

There is no limitation $\mathrm{cn}$ the length of the abstract. However, the suggested length is from 150 to 225 words.

14. KEY WORDS: Key words are technically meaningful terms or short phrases that characterize a report and may be used a 8 index entries for cataloging the report. Key words must be aelected so that no security classification is required. Identi. fiers, auch as equipment model designation, trade name, militan project code name, geographic location, may be used as key words but will be followed by an indication of technical context. The assignment of links, rules, and weights is optional. 
Distribution Iist

IAMONT GEOLOGICAI OBN JRVATORY

COIUIBIA UITV H'̌SITY

- ILISADES, NISW YORK

DEPARTIENT OF DEFENSE

Director of Defense Research and Engineering

Office of the Secretary of Defense

i.ashington, D.C. 20301

Attn: Office, Assistant Director (iesearch)

NAVY

Office of Naval Research

Ocean Science \& Technology Group

Department of the Navy

Washington, D.C. 20360

Attn: Undersea Programs

(Code 466)

Attn: Field Projects

(Code 418)

Attn: Surface \& imphibious Frogrums

(Code 463)

Attn: Geography Branch

(Code 414)

Commanding Officer

Office of Naval Research Branch

Office

495 Summer Street

Boston, liass. 02210

Commanding Officer

Office of Naval Lesearch Branch

Office

1030 East Green Street

Pasadena, Calif. 91101

Commanding Officer

Office of Naval Fesearch Branch

219 South Dearborn street Chicago, Illinois 60604
Commanding Officer

Office of Naval Research Branch Office

Navy 100, Fleet Post Office

New York, N.Y. 09510

Director

Naval Research Laboratory

Washington, D.C. 20390

Attn: Code 5500

Commander

2 U.S. Naval Oceanographic

1 Tashington, D.C. 20390

Attn: Code 1640 (Iibrary)

Attn: Code 031

Attn: Code 70

Attn: Code 90

1 West Coast Support Group

U.S. Naval Oceanographic

$$
\text { Office }
$$

c/o U.S. Navy Electronics Laboratory

San Diego, Calif. 92152

U.S. Navy Electronics

Point Loma

Laboratory

San Diego, California

1 U.S. Naval Oceanographic

$$
\text { Office }
$$

Iiaison Officer (Code 332) Anti-Submarine Tarfare Force U.S. Atlantic Fleet

Norfolk, Virginia 23511 
U.S. Naval Oceanographic Office Iiaison Officer Anti-Submarine Warfare Force

Fleet Post Office Pacific

San Francisco, Calif. 96610

Commander-in-Chief

Submarine Force Pacific Fleet

Fleet Post Office

San Francisco, Calif. 96610

\section{Chief}

Naval Ordnance Systems Command

Departmen' of the Navy

'ashington, D.C. 20360

Commander

Submarine Development Group Two

Via: CDR Submarine Force

U.S. Atlantic Fleet

c/o Fleet Post Office

New York, I. Y.

Chief

INaval ir Systems Command

Department of the Navy

Washington, D.C. 20360

Attn: AIR $370 \mathrm{E}$

Office of the U.S. Naval

$$
\text { Weather Service }
$$

Washington Navy Yard

Washington, D.C. 20390

Chief

Naval Facilities engineering Command

Department of the Navy

Washington, D.C. 20390

Attn: Code 70

Commander-in-Chief

Pacific Fleet

Fleet Post Office

San Francisco, Calif. 96610
U.S. Navy Electronics

Laboratory

San Diego, Calif. 92152

A.ttn: Code 3102

Attn: Code $3060 \mathrm{C}$

Commanding Officer \& Director

U.S. Naval Civil Engineering Laboratory

Hueneme, Calif. 93041

Commanding Officer

Pacific Missile Range

Pt. Mugu, Hueneme, Calif. I

1 Commander, Naval Ordnance Laboratory

White Oak

Silver Spring, Md. 209101

Commanding Officer

Naval Oranance Test

Station

China Lake, Calif.93557 I

Commanding Officer

Naval Radiological Defense Laboratory

1 San Francisco, Calif.94135 I

Commanding Officer

U.S. Naval Underwater

Ordnance Station

1 Newport, Rhode Island 02884

Chief

Naval Ship Systems Command

Department of the Navy

1 Washington, D.C. 20360

1 Attn: Code OOVI-K

Code 2021

Commanding Officer

U.S. Navy $\Lambda$ ir Development

1

Warminster, Penna.18974 I

Attn: NADC Library 
U.S. Fleet Weather Central

Joint Typhoon Varning Center COIINAVMARI INAS BOX 12

San Francisco, Calif.94101

Chief, Bureau of Naval Weapons

Code RU 222

Navy Department

Washington, D.C.

Superintendent

U.S. Naval Hicademy

Annapolis, Ilaryland 21402

Department of Meteorology \& Oceanography

U.S. Naval Postgraduate School

Monterey, Calif. 93940

Commanding Officer

U.S. Naval Underwater Sound Laboratory

New London, Conn. 06321

Office of Naval Research

346 Broadway

New York 13, New York

Officer-in-Charge

U. S. Fleet Numerical Weather Facility

U.ô. Naval Postgraduate jehool Monterey, Calif. 93940

Commanding Officer

U.S. Navy line Defense I boratory Panama City, Florida 32402

AIR FORCE

Headquarters Air Veather Service ( AWSS TTIPD)

U.S. Air Force

Scott Air Force Base,

Illinois 62225
AFCRI

I.F. Hanscom Field

Bedford, Miass. 01730

ARPYY

Coastal Engineering Research Center

1 Corps of Engineers Department of the Armv Washington, D.C. 20310

1 Army Research Office

Office of the Chief of R \& D

Department of the Army

Washington, D.C. 20310

U.S. Army Beach Er:sion

Board.

5201 Iittle Falls Rd.,N.U.

Washington, D.C. 20016

3 Director

U.S. Army Engineers Vaterways Experiment Station

Vicksburg, Miss. 49097

Attn: Research Center

Library

OTHER GOVERNMENT AGENCIES

Director

1 Arctic Research Laboratory

P.O. Box 1070

Fairbanks, Haska

Committee on Undersea Warfare National Academy of Science 2101 Constitution Ave., N.W. Washington, D.C.

Defense Documentation Center Cameron Station Alexandria, Virginia 
National Research Council 2101 Constitution Ave.,N.W. Washington, D.C. 20418 Attn: Committee on Undersea llarfare

Attn: Committee on Oceanography

Laboratory Director

California Current Resources Labcratory

Bureau of Commercial Fisheries P.O. Box 271

IaJolla, Calif. 92038

Director

Coast \& Geodetic Survey U.S. ESSA

Attn: Office of Hydrography \& Oceanography

Washington Science Center Rockville, Miaryland 20852

Director

Atlantic larine Center

Coast \& Geodetic Survey -

439 West York Street

$$
\text { U.S. ESSA }
$$

Norfolk, Virginia 23510

Director, ESSA

Institute for Oceanography

901 South riami Ave.

Miami, Florida 33130

U.S. ESEA

Geophysical Science Library

Vashington Science Center

Rockville, Maryland 20852

Commanding Officer

Coast Guard Oceanographic Unit

Bldg. 159, Navy Yard Annex

Tashington, D.C. 20390
Chief, Office of Marine Geology \& Hydrology

2 U. 3. Geological Survey

Ilenlo Park, Calif. 94025 I

Director

Pacific Marine Center

Coast and Geodetic Survey U.S. ESSA

1801 Fairview Ave., East

Seattle, Washington $98102 \quad 1$

1 Geological Division

Marine Geology Unit

U.S. Geological Survey

Washington, D.C. 20240

National Science Foundation Office of Sea Grant Programs $1800 \mathrm{G}$ Street, N.W.

I Washington, D.C. 20550 I

Laboratory Director

Bureau of Commercial

Fisheries

Biological Laboratory

450-B Jordon Hall

1 Stanford, Calif. 94035

Bureau of Commercial Fisheries U.S. Fish \& ildlife vervice P.O. Box 3830

1 Honolulu, Hawaii 96812 I

Laboratory Director

Biological Laboratory

Bureau of Commercial Fisheries P.O. Box 1155

1 Juneau, Alaska 99801 I

Laboratory Director

Biological Laboratory

Bureau of Commercial Fisheries

1 P.O. Box 6

loods Fole, Mass. $02543 \quad I$ 
Laboratory Director

Biolorical Ieboratory

Bureau of Commercial Fisheries

P.O. Box 280

Brunswick, Georgia 31521

Laboratory Director

Tuna Resources Laboratory

Bureau of Commercial Fisheries P.O. Box 271

Ia Jolla, Calif. 92038

Bureau of Commercial Fisheries \& iilalife

U.S.Hish \& Tilalife service

iibrarian

Sandy Hook Marine Laboratory

P.O. Box 428

Highlands, Itew Jersey 07732

Director

National Oceanographic Data Center

Nashington, D.C. 20390

Laboratory Director

Biological Laboratory

Bureau of Commercial Fisheries \#75 Virginia Beach Drive

liami, Florida 33149

Director, Bureau of Commercial Tisheries

U.S. Fish R: Tildife Service

Dept. of the Interior

Vashington, D.C. 20240

Burea of Commercial Fisheries Biological taboratory,

Oceanography

2725 Iiontlake Boulevard, East

Seattle, ashington 98102

Dr. Gene A. Rusnak

U.S. Geological Survey

Iíarine Geology \& Hydrology

345 liddlefield Kroad

Tienlo Park, Calif. 94025
Assistant Director

Oceanography liuseum of Natural History

Smithsonian Institution

1 Washincton, D.C. 20560

Advanced Research Projects

The Pentagon Agency

Attn: Nuclear Test

Detection Office

RESEARCH IABORATORIES

Director

Voods Hole Oceanographic

Institution

Woods Hole, Niass. 02543

Director

Narragansett llarine

1 Laboratory

Univ. of Rhode Island

Kingston, Rhode Island

02881

Gulf Coast Research Laboratory

1 Ocean Springs, IIississippi 39564

Attn: Librarian

Bell Telephone Laboratories, Inc.

$1 \quad$ Whippany, New Jersey

Attn: Dr. W.A. Tyrrell

Chairman, Dept. of

Meteorology \& Oceanography

New York University

1 New York, N.Y. 10453 I

Director

Lamont Geological Observatory Columbia University Palisades, New York 109641

Director

Hudson Laboratories

145 Palisade Street

Dobbs Ferry, New York 10522 
Resident Rep.

Office of Naval Research

Hudson Laboratories

145 Palisade Street

Dobbs Ferry, New York 10522

Great Iakes Research Division

Institute of Science \& Techrology University of Pichigan

Ann Arbor, Michigan 48105

Department of Fhysics

Northern Iichigan Univ.

Marquette, Michigan 49855

Director

Chesapeake Bay Institute

John Hopkins University

Baltimore, Ilaryland 21218

Allan Hancock Foundation

University Park

Los ingeles, Calif. 90007

liarine Physical Laboratory

University of California

San Diego, Calif.

Head, Department of Oceanography

Oregon State University

Corvallis, Oregon 97331

Defense Research Laboratory

University of Texas

Austin, Texas

Via: ONR Resident Rep.

Head, Department of Oceanography

University of lashington

Seattle, Vashington 98105

Director

Ilawaiian Marine Laboratory

University of Hawaii

Honolulu, Hawaii 96825
Department of Engineering

University of California

Berkeley, Calif. 94720

1

I Applied Physics Laboratory

University of lashington

1013 N.E. Fortieth st.

Seattle, Washington 981051

1 Physical Oceanographic

Nova University

Laboratory

1786 S.E. Fifteenth Ave.

1 Fort Lauderdale, Fla.33316 I

Serials Department

University of Illinois Library

Urbana, IIl. 61801

1

1

Department of Geophysical

Sciences

University of Chicago

1 Chicago, Ill. 60637

1

Coastal Ingineering Laboratory

University of Florida

I Gainesville, Florida 326011

riarine Science Center

Lehigh University

1 Bethlehem, Penna. 18015 I

Institute of Geophysics

Univ. of Hawaii

Honolulu, Hawaii 96825

1

Mr. I. A. Gast

Wildlife Building

Humboldt State College

1 Arcata, Calif. 95521 

Department of Geology \&

Genphysics

Ilassachusetts Institute of

Technology

Cambridge, Ilass. 02139

1

Division of Engineering \&

Harvard University

ipplied Fhysics

Cambridge, Mass. 02138

Department of Geology

Yale University

New Haven, Conn. 06520

Westinghouse Ilectric Corp.

$1625 \mathrm{~K}$ Street, N.T.

Washington, D.C. 20006

Director

Institute of liarine Sciences

University of Hlaska

College, Alaska 99735

Director, Marine Leboratory

University of Iiiami

"i Rickenbacker Causeway

Miami, Florida 33149

University of Connecticut

Southeastern Branch, ivery Point Groton, Conn. 06330

Attn: Library Staff

Head, Dept. of Oceanocraphy \& ileteorology

Texas A \& ir University

College Station, Texas 778432

Director

Scripps Institution of

Ia Jolla, California 92038

Director, Dept. of Oceanography

Florica ktantic University

Boca Raton, Florida 

